\title{
Effects of antidiabetic drugs on left ventricular function/dysfunction: a systematic review and network meta-analysis
}

\author{
Da-Peng Zhang, Li Xu* ${ }^{*}$, Le-Feng Wang, Hong-Jiang Wang and Feng Jiang
}

\begin{abstract}
Background: Although a variety of antidiabetic drugs have significant protective action on the cardiovascular system, it is still unclear which antidiabetic drugs can improve ventricular remodeling and fundamentally delay the process of heart failure. The purpose of this network meta-analysis is to compare the efficacy of sodium glucose cotransporter type 2 (SGLT-2) inhibitors, dipeptidyl peptidase-4 (DPP-4) inhibitors, glucagon-like peptide-1 (GLP-1) agonists, metformin (MET), sulfonylurea (SU) and thiazolidinediones (TZDs) in improving left ventricular (LV) remodeling in patients with type 2 diabetes (T2DM) and/or cardiovascular disease (CVD).

Methods: We searched articles published before October 18, 2019, regardless of language or data, in 4 electronic databases: PubMed, EMBASE, Cochrane Library and Web of Science. We included randomized controlled trials in this network meta-analysis, as well as a small number of cohort studies. The differences in the mean changes in left ventricular echocardiographic parameters between the treatment group and control group were evaluated.

Results: The difference in the mean change in LV ejection fraction (LVEF) between GLP-1 agonists and placebo in treatment effect was greater than zero $(\mathrm{MD}=2.04 \%[0.64 \%, 3.43 \%])$; similar results were observed for the difference in the mean change in LV end-diastolic diameter (LVEDD) between SGLT-2 inhibitors and placebo (MD = - $3.3 \mathrm{~mm}$ [5.31, -5.29]), the difference in the mean change in LV end-systolic volume (LVESV) between GLP-1 agonists and placebo $(\mathrm{MD}=-4.39 \mathrm{ml}[-8.09,-0.7])$; the difference in the mean change in E/e' between GLP-1 agonists and placebo $(M D=-1.05[-1.78,-0.32]) ;$ and the difference in the mean change in $E / e^{\prime}$ between SGLT-2 inhibitors and placebo $(\mathrm{MD}=-1.91[-3.39,-0.43])$.

Conclusions: GLP-1 agonists are more significantly associated with improved LVEF, LVESV and E/e', SGLT-2 inhibitors are more significantly associated with improved LVEDD and E/e', and DPP-4 inhibitors are more strongly associated with a negative impact on LV end-diastolic volume (LVEDV) than are placebos. SGLT-2 inhibitors are superior to other drugs in pairwise comparisons.
\end{abstract}

Keywords: GLP-1 agonists, SGLT-2 inhibitors, DPP-4 inhibitors, Left ventricular remodeling, LVEF

*Correspondence: imxuli@hotmail.com

Heart Center and Beijing Key Laboratory of Hypertension, Beijing Chaoyang Hospital, Capital Medical University, No. 8, Gongti South Road, Chaoyang District, Beijing 100020, China

\begin{abstract}
Background
In recent years, many studies have found that a variety of antidiabetic drugs exert significant protective action on the cardiovascular system, a mechanism that may be partially independent of hypoglycemic effects. This undoubtedly sounds like exciting news for diabetic patients, especially those with cardiovascular disease, although the cardiovascular protective mechanism
\end{abstract}


is not clear. The sodium glucose cotransporter type 2 (SGLT-2) inhibitor empagliflozin has been demonstrated to reduce cardiovascular mortality by $38 \%$ and heart failure (HF) hospitalizations by $35 \%$ in patients with type 2 diabetes (T2DM) in the EMPA-REG OUTCOMES clinical trial $[1,2]$. An early nonrandomized pilot study showed improved left ventricular function when glucagon-like peptide-1 (GLP-1) agonists were infused in patients with acute myocardial infarction and HF [3]. Two small randomized controlled trials showed that GLP-1 agonist infusion exerted a positive effect on patients with ischemic heart disease [4, 5]. Traditional hypoglycemic drugs such as metformin (MET) have also been found to have a positive effect on cardiovascular protection [6-8]. A 2019 meta-analysis found that MET reduced cardiovascular mortality and the incidence of cardiovascular events in diabetic patients [9]. These results suggest that we should prioritize drugs that have some cardiovascular protective effects when choosing a treatment for diabetes.

The mitigation of left ventricular (LV) remodeling was paralleled by improvements in LV systolic performance. If ventricular remodeling can be delayed, the process of HF can be fundamentally delayed. Recently, a study found that empagliflozin-treated pigs showed higher LV ejection fraction (LVEF) and significantly greater contractile reserve than control animals [10]. Empagliflozin improved adverse anatomic LV remodeling, enhanced left ventricular systolic function, and inhibited neurohormonal activation. Liraglutide [11], a GLP-1 agonist, slightly increased LVEF in patients with ST-segment elevation myocardial ischemia (STEMI) who underwent direct percutaneous coronary intervention. Alogliptin, a DPP-4 inhibitor, improves coronary flow reserve (CFR) and LVEF in patients with T2DM with coronary artery disease (CAD), and the improvement in CFR was associated with increased LV systolic function [12]. Ventricular remodeling is an important determinant of patient morbidity and longterm prognosis [13]. Although many antidiabetic drugs have the effect of reducing cardiovascular death and adverse cardiovascular events, it is still unclear which antidiabetic drugs can improve ventricular remodeling and fundamentally delay the process of HF. If drugs can be found to improve ventricular remodeling, it will be of great significance for patients with T2DM with cardiovascular disease (CVD).

The purpose of this network meta-analysis is to compare the efficacy of SGLT-2 inhibitors, DPP-4 inhibitors, GLP-1 agonists, MET, sulfonylurea (SU) and thiazolidinediones (TZDs) in improving LV remodeling in patients with T2DM and/or CVD.

\section{Methods}

\section{Protocol and guidance}

This systematic review and network meta-analysis followed the Preferred Reporting Items for Systematic Reviews and Meta analyses (PRISMA) guidelines [14].

\section{Eligibility criteria}

We included randomized controlled trials with parallel group or crossover designs in this network meta-analysis, as well as a small number of cohort studies. All trials had to include treatment with one of the following 6 drugs or multiple drugs: MET, GLP-1 agonists, DPP-4 inhibitors, SGLT-2 inhibitors, TZDs and SU. The control group was treated with placebo or one of the 6 drugs. Study participants were either type 2 diabetic patients with or without CVD or patients with CVD alone. The outcome of the included studies must contain at least one of the following 6 cardiac function and structure measures: LVEF, LV end-diastolic diameter (LVEDD), LV end-systolic diameter (LVESD), LV end-diastolic volume (LVEDV), LV end-systolic volume (LVESV), LV mass index (LVMI), early diastolic velocity $\left(\mathrm{e}^{\prime}\right)$, early diastolic to late diastolic velocities ratio $(\mathrm{E} / \mathrm{A})$ and mitral inflow $\mathrm{E}$ velocity to tissue Doppler $\mathrm{e}^{\prime}$ ratio $\left(\mathrm{E} / \mathrm{e}^{\prime}\right)$.

\section{Information sources and search strategy}

We searched articles published before October 18, 2019, regardless of language or data, in 4 electronic databases: PubMed, EMBASE, Cochrane Library and Web of Science. The articles were selected by manual screening.

The following terms were used in the search: ventricular remodeling OR cardiac reverse remodeling OR CRR OR cardiac remodeling OR left ventricular remodeling OR left ventricular dysfunction OR LVD OR ejection fraction OR EF OR left ventricular ejection fraction OR LVEF OR end-diastolic volume OR EDV OR end-diastolic dimension OR EDD OR end-systolic volume OR ESV OR end-systolic dimension OR ESD OR LVEDD OR left ventricular end-diastolic dimension OR LVEDV OR left ventricular end-diastolic volume OR LVESD OR left ventricular end-systolic dimension OR LVESV OR left ventricular end-systolic volume OR left ventricular diameter OR left ventricular volume OR left ventricular mass index OR LVMI OR left atrial volume OR LAV OR left atrial volume index OR LAVI) AND (Dipeptidyl peptidase-4 inhibitors OR DPP-4 inhibitors OR Sodium-Glucose Cotransporter-2 Inhibitors OR SGLT-2 inhibitors OR Glucagon-like peptide-1 agonists OR GLP-1 agonists OR exenatide OR Lyxumia OR liraglutide OR Saxenda OR Tanzeum OR albiglutide OR Trulicity OR dulaglutide OR canagliflozin OR dapagliflozin OR empagliflozin OR ertugliflozin OR ipragliflozin OR luseogliflozin 
OR tofogliflozin OR sitagliptin OR vildagliptin OR saxagliptin OR alogliptin OR linagliptin OR gemigliptin OR teneligliptin OR metformin OR sulfonylureas OR glibenclamide OR glyburide OR glybenzcyclamide OR gliquidone OR Gliclazide OR glipizide OR Glucotrol OR gliclazide OR Gliclarizonaide OR glimepiride OR Amaryl OR acarbose OR Precose OR air conditioningarbose OR miglitol OR Glyset OR voglibose OR Basen OR repaglinide OR nateglinide OR mitiglinide.

\section{Study selection}

Two methodologically trained independent reviewers screened titles and abstracts to determine whether they met the eligibility criteria. The reviewers read the full text and extracted relevant data after consensus was reached. Any differences were resolved through discussion and arbitration, if necessary, by a third reviewer. The reasons for inclusion or exclusion are recorded in detail. Case reports, letters and minutes of meetings were excluded. The PRISMA flow diagram was used to summarize the study selection processes.

\section{Data extraction}

Two investigators used a predefined data extraction sheet to independently extract data from each included study, such as authors, publication year, study design, population, subject ages, intervention, male sex, sample size, grouping and number of people in the group, baseline and endpoint data, including counts and effect estimates (mean $\pm \mathrm{SD}$ ), country, follow-up months, title, and conclusion. The third investigator independently reviewed the data to ensure accuracy. If no data in digital format were available, we used the free software Plot Digitizer to estimate data from the graphs.

\section{Definition of outcomes}

The outcome of this meta-analysis was the difference in the mean change in echocardiographic parameters between the treatment group and control group. The echocardiographic parameters included LVEF, LVEDD, LVESD, LVEDV, LVESV, LVMI, $\mathrm{e}^{\prime}, \mathrm{E} / \mathrm{A}$ and E/e'.

\section{Statistical analysis}

We used the network meta-analysis approach to evaluate the comparative effect by combining direct and indirect evidence of all relevant treatment effects. To visualize network geometry and node connectivity, we summarized the geometry of the evidence network using network plots. We conducted a network meta-analysis of the comparative efficacy using a multivariate random-effects (restricted maximum likelihood estimation) meta-analysis model. For all treatment comparisons, we present summary mean differences and $95 \%$ confidence intervals.
To obtain treatment hierarchies, we used a parametric bootstrap procedure with 5000 resamples to compute ranking probabilities. Mean rankings as well as surface under the cumulative ranking curve (SUCRA) values were computed for each treatment. We checked the consistency of the network using local and global inconsistency tests. The local inconsistency test evaluates the loop inconsistency of all the triangle loops on the network. Global inconsistency is a goodness-of-fit test. If any relevant sources of bias were found, we performed sensitivity analyses. All analyses were conducted in Stata/SE, version 14.

\section{Assessment of risk of bias in individual studies}

Each study was evaluated using the Cochrane tool. Potential sources of bias include random sequence generation, allocation concealment, blinding of participants and staff, blinding of outcome assessors, incomplete outcome data, and selective reporting. Each trial received a study level score of low, high, or unclear risk of bias for each domain. Two authors independently conducted this assessment, and discrepancies were resolved by consensus.

\section{Assessment of small study effects}

To evaluate the presence of small study effects, we visually inspected comparison-adjusted funnel plots for each outcome. We produced funnel plots for all comparisons concerning the difference in LVEF change between treatment and placebo.

\section{Results}

\section{Study selection}

The initial search of 4 databases yielded 1774 articles. We obtained 91 articles after reading the title and abstract, excluding duplicates and irrelevant articles. After screening the full texts manually, 43 articles were excluded for reasons including study design $(n=10)$, insufficient information for a meta-analysis $(\mathrm{n}=13)$, no human subjects $(n=5)$, no comparison group included in the trial $(\mathrm{n}=3)$, review article $(\mathrm{n}=2)$, case report $(\mathrm{n}=2)$, and conference abstract $(n=8)$. Eventually, 48 studies were included in this network meta-analysis (Fig. 1).

\section{Study characteristics}

In this network meta-analysis, 48 studies were included, comprising a total sample size of 4790 participants. The 48 studies included 36 randomized controlled trials (RCTs) and 12 cohort studies. Among them, 7 trials concerned MET, 25 trials involved GLP-1 agonists, 10 studies reported DPP-4 inhibitors, 3 studies discussed SGLT-2 inhibitors, 8 studies referred to TZDs and 5 studies covered SU. Among them, 39 studies reported pairwise comparisons with placebo, 2 were three-arm studies 

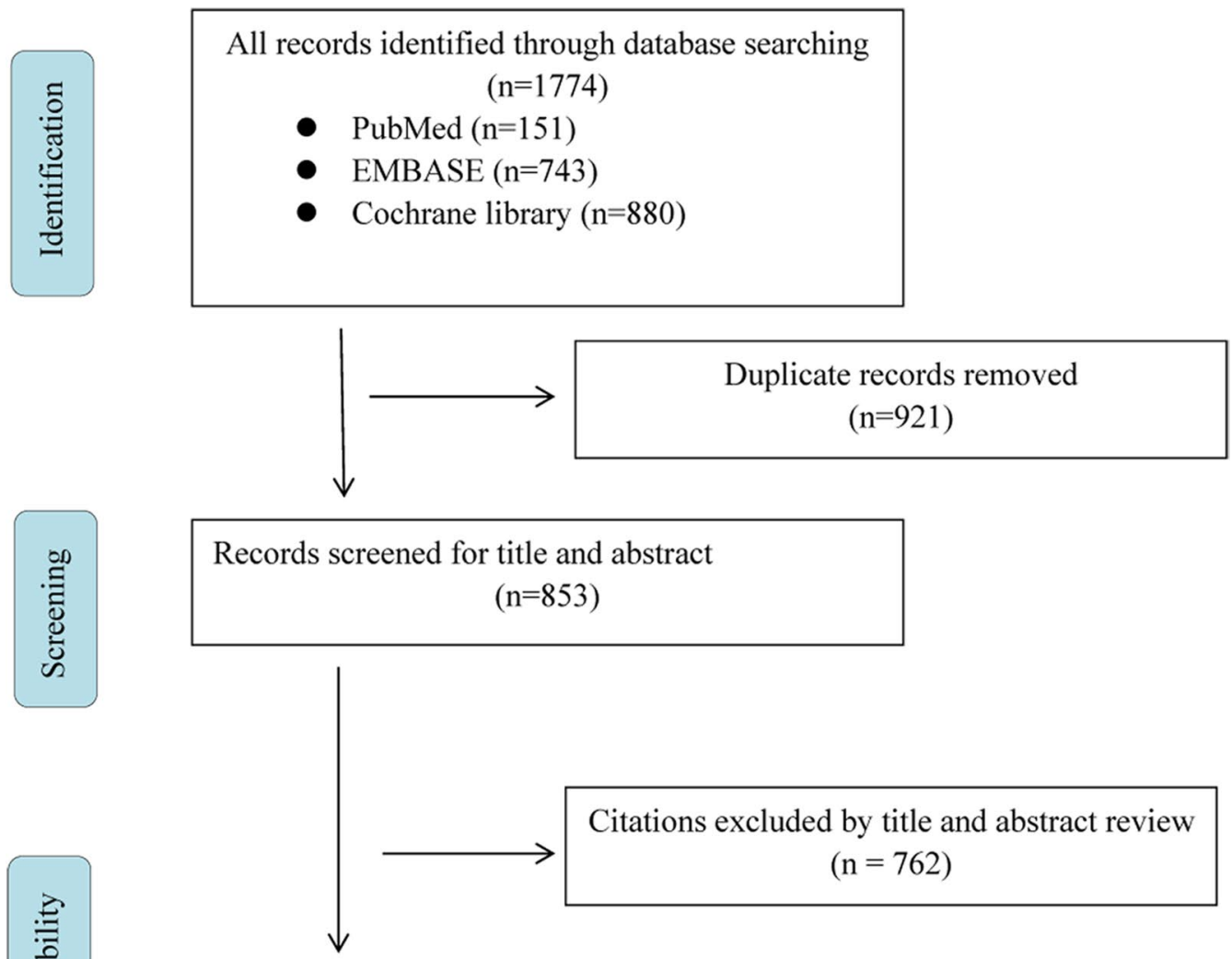

Full-text records assessed for eligibility $(\mathrm{n}=91)$

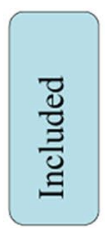

Full-text records excluded, with reasons $(n=43)$

- Study design $(\mathrm{n}=10)$

- Insufficient information for a metaanalysis $(\mathrm{n}=13)$

- No human $(\mathrm{n}=5)$

- No comparison group included in the trial $(n=3)$

- Review $(\mathrm{n}=2)$

- Case report $(\mathrm{n}=2)$

- Conference abstract $(\mathrm{n}=8)$

Records included in meta-analysis

$$
(n=48)
$$

Fig. 1 Flowchart of study selection 
(placebo was one arm), and 7 were comparisons between two treatments. Participants in 17 trials were patients with T2DM, participants in 9 studies were patients with CVD, and participants in the remaining 22 studies were patients with T2DM and CVD. The summary data of each included study are shown in Table 1 , and the network plot is shown in Fig. 2.

\section{Risk of bias within studies}

Among the 10 cohort studies, high risk was observed in randomization and blinding. Among the $36 \mathrm{RCTs}$, high risk was observed in the blinding of participants and staff, as 11 were open-label, but most of their blinding of outcome assessors was at low risk. No risk of incomplete outcome data or selective reporting was identified in any study (Additional file 1: Figure S1 and Additional file 2: Figure S2).

\section{Synthesis of results}

\section{Difference in mean change in LVEF}

First, the difference in the mean change in LVEF between GLP-1 agonists and placebo in treatment effect was greater than zero (mean difference $(\mathrm{MD})=2.04 \%[95 \%$ confidence interval (CI) $0.64 \%, 3.43 \%]$ ), indicating that GLP-1 agonists were more significantly associated with improved LVEF than placebo. Second, there was no difference in the mean change in LVEF between any of the other 5 drugs (i.e., MET, DPP-4 inhibitors, SGLT-2 inhibitors, TZDs, and $\mathrm{SU}$ ) and placebo in treatment effect, as well as no difference in treatment effect in the pairwise comparison between any two of the 6 drugs (Fig. 3a, Table 2a).

We performed 2 subgroup analyses of T2DM + CVD and CVD without T2DM and obtained the results as shown in Fig. 3b, c. No significant difference in LVEF improvement was demonstrated between GLP-1 agonists and placebo in the CVD without T2DM subgroup, with a difference in mean change of $-0.09(-2.69,2.52)$. However, GLP-1 agonists were shown to be more significantly associated with LVEF improvement than placebo in the $\mathrm{T} 2 \mathrm{DM}+\mathrm{CVD}$ subgroup, in which the difference in mean change was $2.56(0.65,4.47)$. This finding showed that GLP-1 agonists had a better effect on diabetic patients with CVD than on patients with CVD alone. No significant difference in change in LVEF was demonstrated in the 2 subgroups between other drugs and placebo or in pairwise comparisons.

\section{Difference in mean change in LVEDD}

First, the difference in the mean change in LVEDD between SGLT-2 inhibitors and placebo in treatment effect was less than zero $(\mathrm{MD}=-3.3 \mathrm{~mm}[95 \% \mathrm{CI}-5.31$, -5.29], indicating that SGLT-2 inhibitors were more significantly associated with improved LVEDD than placebo. Second, there was no difference in the mean change in LVEDD between any of the other 5 drugs (MET, GLP-1 agonists, DPP-4 inhibitor, TZDs, and SU) and placebo in the treatment effect. Third, the MDs in pairwise comparisons between two drugs-STLG2 vs GLP-1 agonists, STLG2 vs DPP-4 inhibitors, and TZDs vs STLG2-in treatment effect were $-3.35 \mathrm{~mm}[95 \% \mathrm{CI}-5.57,-1.14]$, $-3.62 \mathrm{~mm} \mathrm{[95 \%} \mathrm{CI}-5.99,-1.24]$, and $4.2 \mathrm{~mm}[95 \% \mathrm{CI}$ $1.13,7.27]$, respectively, showing that the improved effect of STLG2 on LVEDD was obviously better than those of GLP-1 agonists, DPP-4 inhibitors, and TZDs. There was no difference in the mean change in LVEDD before and after the use of any pair of other drugs in treatment effect (Fig. 4a, Table 2b).

\section{Difference in mean change in LVESD}

There was no difference in mean change in LVESD between each of the 6 drugs and placebo or in pairwise comparison between any two of the 6 drugs in treatment effect (Fig. 4b, Table 2c).

\section{Difference in mean change in LVEDV}

First, the difference in the mean change in LVEDV between DPP-4 inhibitors and placebo in treatment effect was significantly larger than zero $(M D=18.4 \mathrm{ml}$ [95\% CI 4.14, 32.67]), indicating that DPP-4 inhibitors had a negative impact on LVEDV. Second, there was no difference in the mean change in LVEDV between any of the other 5 drugs (MET, GLP-1 agonists, SGLT-2 inhibitors, TZDs, and SU) and placebo, in treatment effect. Third, the MD between the two drugs-DPP-4 inhibitors vs GLP-1 agonists-in treatment effect was $19.8 \mathrm{ml}$ [95\% CI 5.14, 34.46], which was significant, indicating that DPP-4 inhibitors were more significantly associated with a negative impact on LVEDV than GLP-1 agonists. There was no difference in the mean change in LVEDV before and after the use of any pair of other drugs in treatment effect (Fig. 5a, Table 2d).

\section{Difference in mean change in LVESV}

First, the difference in the mean change in LVESV between GLP-1 agonists and placebo in treatment effect was less than zero $(\mathrm{MD}=-4.39 \mathrm{ml}[95 \% \mathrm{CI}$ $-8.09,-0.7])$ with significance, indicating that GLP-1 agonists were more significantly associated with the improvement of LVESV than placebo. Second, there was no difference in the mean change in LVESV between any of the other 5 drugs (MET, SGLT-2 inhibitors, DPP-4 inhibitors, TZDs, and SU) and placebo, in the treatment effect. Third, the MD between the two drugs-DPP-4 inhibitors vs GLP-1 agonists-in treatment effect was $15.75 \mathrm{ml}$ [95\% CI 0.00. 31.5] with 
Table 1 Characteristics of included studies

\begin{tabular}{|c|c|c|c|c|c|c|c|}
\hline Study & Year & Age & Male\% & Patients & Sample size & Treatment & Country \\
\hline Al Ali et al. [15] & 2016 & $57.9(11.4)$ & 80.5 & CVD & 237 & MET & Netherlands \\
\hline Arturi et al. [16] & 2017 & $59.5(9)$ & 70.0 & $\mathrm{~T} 2 \mathrm{DM}$ & 32 & GLP-1 agonist, DPP-4 inhibitor & Italy \\
\hline Bizino et al. [17] & 2019 & $60(6)$ & 61.0 & $\mathrm{~T} 2 \mathrm{DM}$ & 49 & GLP-1 agonist & Netherlands \\
\hline Bonora et al. [18] & 2019 & $65.7(5.9)$ & 66.7 & T2DM & 30 & SGLT-2 inhibitor & Italy \\
\hline Brenne et al. [19] & 2016 & $61.3(11.0)$ & 79.3 & CVD & 173 & DPP-4 inhibitor & Austria \\
\hline Chen et al. [20] & 2017 & $66(5)$ & 100.0 & $\mathrm{~T} 2 \mathrm{DM}+\mathrm{CVD}$ & 23 & GLP-1 agonist & Netherlands \\
\hline Chen et al. [21] & 2016 & $58.0(11.7)$ & 76.0 & $\mathrm{~T} 2 \mathrm{DM}+\mathrm{CVD}$ & 90 & GLP-1 agonist & China \\
\hline Chen et al. [22] & 2015 & $57.7(11.3)$ & 67.0 & $\mathrm{~T} 2 \mathrm{DM}+\mathrm{CVD}$ & 92 & GLP-1 agonist & China \\
\hline Cohen et al. [23] & 2019 & $62.9(6.8)$ & 58.8 & T2DM & 25 & SGLT-2 inhibitor & Australia \\
\hline Ghazzi et al. [24] & 1997 & $54(10.8)$ & 54.0 & T2DM & 154 & TZDs, SU & USA \\
\hline Giles et al. [25] & 2008 & $64.2(9.92)$ & 70.2 & $\mathrm{~T} 2 \mathrm{DM}+\mathrm{CVD}$ & 518 & TZDs, SU & USA \\
\hline Halbirk et al. [26] & 2010 & $61(3)$ & 86.7 & CVD & 15 & GLP-1 agonist & Denmark \\
\hline Hiramatsu et al. [27] & 2018 & $70.5(5.7)$ & - & $\mathrm{T} 2 \mathrm{DM}+\mathrm{CVD}$ & 98 & GLP-1 agonist, DPP-4 inhibitor & Japan \\
\hline Hiramatsu et al. [28] & 2015 & $68.5(9.4)$ & 86.7 & $\mathrm{~T} 2 \mathrm{DM}$ & 30 & GLP-1 agonist & Japan \\
\hline Jorgensen et al. [29] & 2017 & $57(10)$ & & T2DM & 32 & GLP-1 agonist & Denmark \\
\hline Jorsal et al. [30] & 2017 & $65(9.2)$ & 89.3 & $\mathrm{~T} 2 \mathrm{DM}+\mathrm{CVD}$ & 241 & GLP-1 agonist & Denmark \\
\hline Kato et al. [12] & 2016 & $73.3(6.6)$ & 60.0 & $\mathrm{~T} 2 \mathrm{DM}+\mathrm{CVD}$ & 20 & DPP-4 inhibitor & Japan \\
\hline Kumarathurai et al. [31] & 2016 & $61.8(7.6)$ & 79.0 & $\mathrm{~T} 2 \mathrm{DM}+\mathrm{CVD}$ & 39 & GLP-1 agonist & Denmark \\
\hline Lambadiari et al. [32] & 2018 & $51(12)$ & 66.7 & $\mathrm{~T} 2 \mathrm{DM}$ & 60 & GLP-1 agonist, MET & Greece \\
\hline Lepore et al. [33] & 2016 & $58(10)$ & 74.0 & CVD & 56 & GLP-1 agonist & USA \\
\hline Leung et al. [34] & 2016 & $56(6)$ & 56.0 & $\mathrm{~T} 2 \mathrm{DM}$ & 75 & DPP-4 inhibitor & Australia \\
\hline Lips et al. [35] & 2017 & - & - & $\mathrm{T} 2 \mathrm{DM}+\mathrm{CVD}$ & 38 & GLP-1 agonist & Czech Republic \\
\hline Liu et al. [36] & 2017 & $58(15)$ & 53.3 & $\mathrm{~T} 2 \mathrm{DM}$ & 120 & GLP-1 agonist, MET & China \\
\hline Margulies et al. [37] & 2016 & $62(52-68)$ & 80.0 & $\mathrm{~T} 2 \mathrm{DM}+\mathrm{CVD}$ & 300 & GLP-1 agonist & USA \\
\hline Mcmurray et al. [38] & 2018 & $62.9(8.5)$ & 77.3 & $\mathrm{~T} 2 \mathrm{DM}+\mathrm{CVD}$ & 254 & DPP-4 inhibitor & UK \\
\hline Mohan et al. [39] & 2019 & $64.5(8.9)$ & 84.0 & CVD & 63 & MET & UK \\
\hline Naka et al. [40] & 2010 & $64.3(8.1)$ & 36.0 & $\mathrm{~T} 2 \mathrm{DM}+\mathrm{CVD}$ & 81 & TZDs & Greece \\
\hline Nielsen et al. [41] & 2019 & $66(7)$ & 94.4 & CVD & 36 & GLP-1 agonist & Denmark \\
\hline Nikolaidis et al. [42] & 2004 & $58(3)$ & 70.0 & $\mathrm{~T} 2 \mathrm{DM}+\mathrm{CVD}$ & 21 & GLP-1 agonist & USA \\
\hline Nogueira et al. [43] & 2014 & $57(7)$ & 50 & $\mathrm{~T} 2 \mathrm{DM}$ & 29 & DPP-4 inhibitor & Brazil \\
\hline Nozue et al. [44] & 2016 & $68(10)$ & 100.0 & $\mathrm{~T} 2 \mathrm{DM}+\mathrm{CVD}$ & 15 & GLP-1 agonist & Japan \\
\hline Nystrom et al. [45] & 2017 & $61(7.6)$ & 72.7 & $\mathrm{~T} 2 \mathrm{DM}+\mathrm{CVD}$ & 62 & GLP-1 agonist, SU & Sweden \\
\hline Oe et al. [46] & 2015 & $67.8(10.5)$ & 50.0 & $\mathrm{~T} 2 \mathrm{DM}+\mathrm{CVD}$ & 80 & DPP-4 inhibitor & Japan \\
\hline Otagaki et al. [47] & 2019 & $70(54-72)$ & 71.0 & $\mathrm{~T} 2 \mathrm{DM}$ & 42 & SGLT-2 inhibitor & Japan \\
\hline Ozawa et al. [48] & 2009 & $67.6(8.8)$ & 75.0 & $\mathrm{~T} 2 \mathrm{DM}+\mathrm{CVD}$ & 54 & $\mathrm{TZD}$ & Japan \\
\hline Sardu et al. [49] & 2018 & $72(7)$ & 71.5 & $\mathrm{~T} 2 \mathrm{DM}+\mathrm{CVD}$ & 559 & GLP-1 agonist & Italy \\
\hline Scognamiglio et al. [50] & 2002 & $61(7)$ & 73.7 & $\mathrm{~T} 2 \mathrm{DM}+\mathrm{CVD}$ & 38 & SU & Italy \\
\hline Sokos et al. [51] & 2006 & $61(4)$ & 58.3 & $\mathrm{~T} 2 \mathrm{DM}+\mathrm{CVD}$ & 21 & GLP-1 agonist & USA \\
\hline St John Sutton et al. [52] & 2002 & $56.1(8.9)$ & 71.0 & $\mathrm{~T} 2 \mathrm{DM}$ & 203 & TZDs, SU & USA \\
\hline Türkmen Kemal et al. [53] & 2007 & $55.92(8.26)$ & 23.1 & T2DM & 46 & TZD, MET & Turkey \\
\hline Van Der Meer et al. [54] & 2009 & $56.8(1.0)$ & - & $\mathrm{T} 2 \mathrm{DM}$ & 78 & TZD, MET & Netherlands \\
\hline Wägner et al. [10] & 2019 & $53.2(9.7)$ & 41.7 & T2DM & 24 & GLP-1 agonist & Spain \\
\hline Wong et al. [55] & 2012 & $64(8)$ & 90.0 & CVD & 61 & MET & UK \\
\hline Woo et al. [56] & 2013 & $59.5(13.2)$ & 89.0 & CVD & 58 & GLP-1 agonist & Korea \\
\hline Yamada et al. [57] & 2017 & $69(8)$ & 69.1 & $\mathrm{~T} 2 \mathrm{DM}$ & 115 & DPP-4 inhibitor & Japan \\
\hline Yamamoto et al. [58] & 2017 & $71(10)$ & 62.0 & $\mathrm{~T} 2 \mathrm{DM}+\mathrm{CVD}$ & 158 & DPP-4 inhibitor & Japan \\
\hline Yokoyama et al. [59] & 2007 & $63(10)$ & 84.0 & $\mathrm{~T} 2 \mathrm{DM}+\mathrm{CVD}$ & 93 & $\mathrm{TZD}$ & Japan \\
\hline Zhang et al. [60] & 2017 & $59.1(11.8)$ & 77.0 & CVD & 52 & GLP-1 agonist & China \\
\hline Total studies [48] & & & & & 4790 & & \\
\hline
\end{tabular}

CVD cardiovascular disease, DPP-4 dipeptidyl peptidase-4; GLP-1 glucagon-like peptide-1, MET metformin, SGLT-2 sodium glucose cotransporter type 2, SU sulfonylurea, T2DM type 2 diabetes mellitus, TZDs thiazolidinediones 


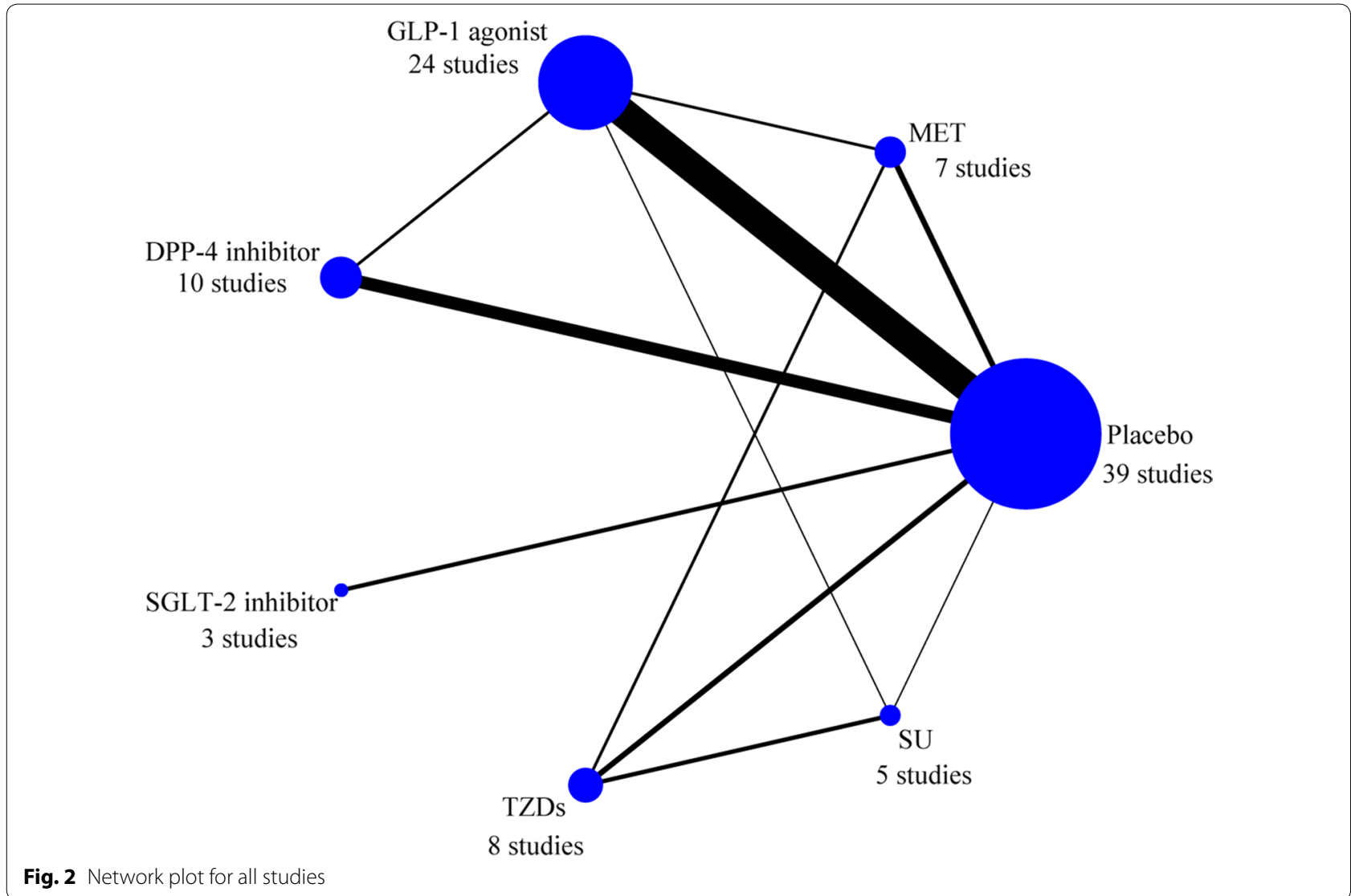

significance, showing that DPP-4 inhibitors were more significantly associated with a negative impact on LVESV than GLP-1 agonists. There was no difference in the mean change in LVESV before and after the use of any pair of other drugs in treatment effect (Fig. 5b, Table 2e).

\section{Difference in mean change in LVMI}

There was no difference in mean change in LVMI between each of the 6 drugs and placebo or in pairwise comparison between any two of the 6 drugs in treatment effect (Fig. 6, Table 2f).

We can make clear from the above discussion that compared with placebo, GLP-1 agonists may notably improve LVEF and LVESV, STLG2 may obviously improve LVEDD, and DPP-4 inhibitors exert a negative impact on LVEDV. SGLT-2 inhibitors are superior to other drugs in pairwise comparison.

\section{Difference in mean change in $e^{\prime}, E / A$ and $E / e^{\prime}$}

GLP-1 agonists were more significantly associated with reducing $\mathrm{E} / \mathrm{e}^{\prime}$ than was placebo, and the difference in mean change was $-1.05(-1.78,-0.32)$. SGLT-2 inhibitors were more significantly associated with reducing $\mathrm{E} / \mathrm{e}^{\prime}$ than was placebo, and the difference in mean change was $-1.91(-3.39,-0.43)$. There was no significant difference in mean change in the treatment effect of $\mathrm{e}^{\prime}$ and E/A between any of the 6 drugs and placebo or in pairwise comparisons between any two of the 6 drugs (Fig. 7, Table 2g-i).

\section{Ranking probabilities}

According to the SUCRA results, the ranking of the efficacy of the 6 drugs and placebo is shown in Additional file 3: Table S1. GLP-1 agonists ranked first in the treatment effect on LVEF and LVMI, and SGLT-2 inhibitors ranked first in treatment effect on LVEDV, LVEDD, LVESD and E/e'. DPP-4 inhibitors ranked first in treatment effect on LVESV and $\mathrm{e}^{\prime}$.

\section{Inconsistency test}

No evidence for statistically significant inconsistency in any of the 6 echocardiographic parameters (global inconsistency tests $\mathrm{P}=0.06$ to 0.89 ) was found. 


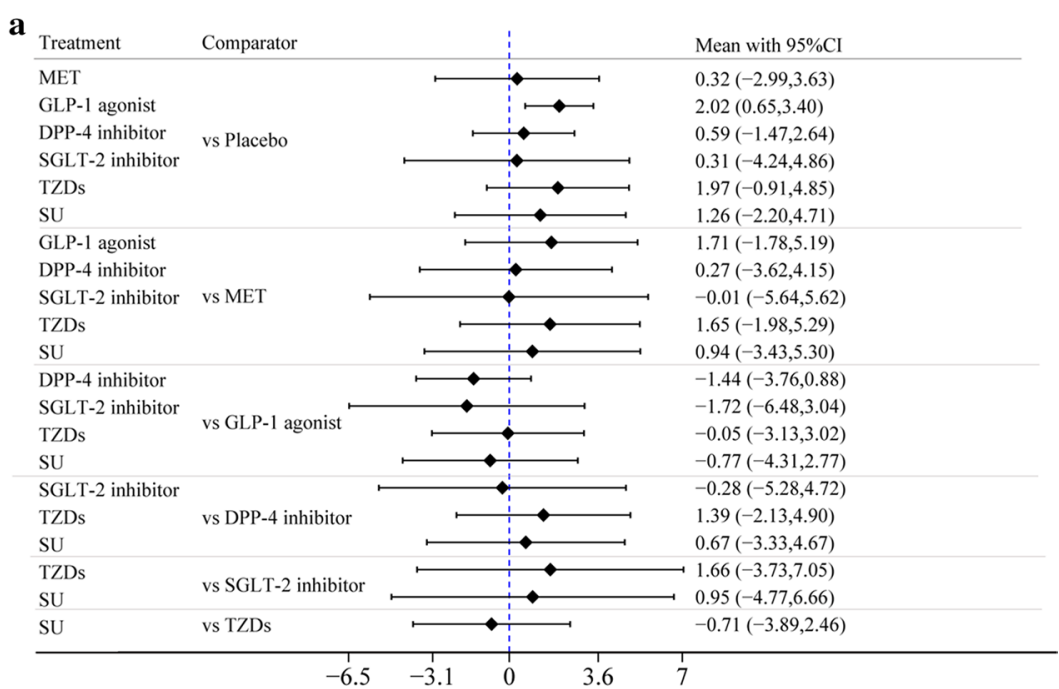

b

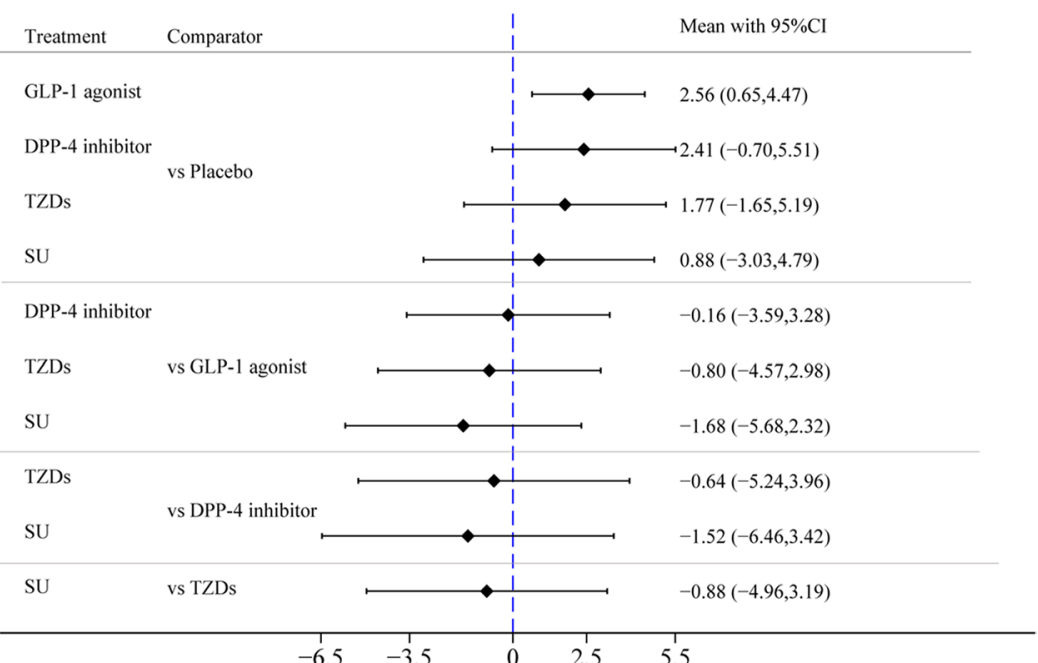

c

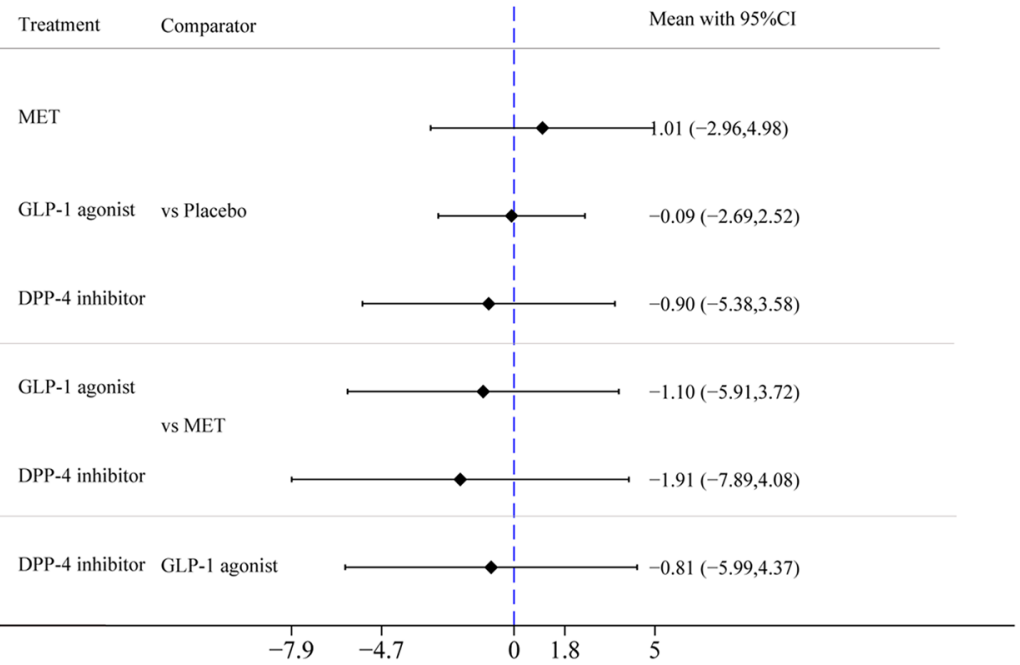

Fig. 3 a Forest plot of mean difference of LVEF\%. $\mathbf{b}$ Forest plot of mean difference of LVEF\% among patients with T2DM + CVD. c Forest plot of mean difference of LVEF\% among patients with CVD without T2DM 
Table 2 Studies included in comparisons. (a) 1 LVEF 44 trails, (b) LVEDD 8 trails, (c) LVESD 6 trails, (d) LVEDV 17 trails, (e) LVESV 15 trails, (f) LVMI 15 trails, (g) E/e' 11 trails, (h) $e^{\prime} 5$ trails, (i) E/A 14 trails included

\begin{tabular}{|c|c|c|}
\hline Treatment & No. of trials & $\begin{array}{l}\text { Total no. } \\
\text { of patients }\end{array}$ \\
\hline \multicolumn{3}{|l|}{ a) LVEF 44 trails } \\
\hline Control & 38 & 1635 \\
\hline DPP-4 inhibitor & 9 & 421 \\
\hline GLP-1 agonist & 24 & 991 \\
\hline MET & 5 & 242 \\
\hline SGLT-2 inhibitor & 3 & 53 \\
\hline SU & 4 & 242 \\
\hline TZDs & 7 & 357 \\
\hline \multicolumn{3}{|l|}{ b) LVEDD 8 trails } \\
\hline Control & 7 & 542 \\
\hline DPP-4 inhibitor & 2 & 126 \\
\hline GLP-1 agonist & 4 & 399 \\
\hline MET & 1 & 30 \\
\hline SGLT-2 inhibitor & 1 & 21 \\
\hline TZDs & 1 & 42 \\
\hline \multicolumn{3}{|l|}{ c) LVESD 6 trails } \\
\hline Control & 6 & 476 \\
\hline DPP-4 inhibitor & 1 & 55 \\
\hline GLP-1 agonist & 3 & 369 \\
\hline SGLT-2 inhibitor & 1 & 21 \\
\hline TZDs & 1 & 42 \\
\hline \multicolumn{3}{|l|}{ d) LVEDV 17 trails } \\
\hline Control & 15 & 915 \\
\hline DPP-4 inhibitor & 2 & 163 \\
\hline GLP-1 agonist & 11 & 621 \\
\hline MET & 2 & 157 \\
\hline SGLT-2 inhibitor & 1 & 17 \\
\hline SU & 1 & 60 \\
\hline TZDs & 2 & 97 \\
\hline \multicolumn{3}{|l|}{ e) LVESV 15 trails } \\
\hline Control & 14 & 858 \\
\hline DPP-4 inhibitor & 1 & 92 \\
\hline GLP-1 agonist & 11 & 621 \\
\hline MET & 3 & 173 \\
\hline TZDs & 2 & 52 \\
\hline \multicolumn{3}{|l|}{ f) LVMI 15 trails } \\
\hline Control & 11 & 416 \\
\hline DPP-4 inhibitor & 5 & 162 \\
\hline GLP-1 agonist & 5 & 92 \\
\hline MET & 2 & 149 \\
\hline SU & 3 & 249 \\
\hline TZDs & 4 & 243 \\
\hline \multicolumn{3}{|l|}{ g) E/e' 11 trails } \\
\hline Control & 9 & 430 \\
\hline DPP-4 inhibitor & 3 & 72 \\
\hline GLP-1 agonist & 6 & 226 \\
\hline
\end{tabular}

Table 2 (continued)

\begin{tabular}{lcc}
\hline Treatment & No. of trials & $\begin{array}{c}\text { Total no. } \\
\text { of patients }\end{array}$ \\
\hline MET & 1 & 118 \\
SGLT-2 inhibitor & 1 & 21 \\
SU & 1 & 22 \\
TZDs & 1 & 42 \\
h) e' 5 trails & & \\
Control & 5 & 341 \\
DPP-4 inhibitor & 2 & 40 \\
GLP-1 agonist & 1 & 122 \\
MET & 1 & 118 \\
TZDs & 1 & 42 \\
i) E/A 14 trails & & \\
Control & 10 & 378 \\
DPP-4 inhibitor & 4 & 82 \\
GLP-1 agonist & 8 & 200 \\
MET & 4 & 217 \\
SGLT-2 inhibitor & 1 & 81 \\
TZDs & 2 &
\end{tabular}

$e^{\prime}$ early diastolic velocity, $E / e^{\prime}$ mitral inflow $E$ velocity to tissue Doppler $\mathrm{e}^{\prime}$ ratio, $E / A$ early diastolic to late diastolic velocities ratio, DPP-4 dipeptidyl peptidase-4; GLP-1 glucagon-like peptide-1, MET metformin, SGLT-2 sodium glucose cotransporter type 2, SU sulfonylurea, TZDs thiazolidinediones

\section{Risk of bias across studies}

The funnel plots were made only for comparisons of differences in mean change in LVEF between the treatment and the placebo groups, as funnel plots are not feasible for those including fewer than 10 studies. Placebo vs. GLP-1 agonists (red A vs. C) and placebo vs. DPP-4 inhibitors (green A vs. D) were included in 24 and 9 studies, respectively, and no evidence of publication bias was found (Additional file 4: Figure S3).

\section{Discussion}

In this network meta-analysis, 48 studies were included, comprising a total sample size of 4790 subjects. The 48 studies included $36 \mathrm{RCTs}$ and 12 cohort studies. We found that compared with placebo, GLP-1 agonists increased LVEF and decreased LVESV and $E / \mathrm{e}^{\prime}$, and SGLT-2 inhibitors decreased LVEDD and E/e'. These results suggested that GLP-1 agonists and SGLT-2 inhibitors could improve ventricular remodeling.

Remodeling is an important determinant of patient morbidity and long-term outcomes. Adverse anatomical remodeling occurs at several levels, including anatomical, metabolic, and neurohormonal remodeling. Anatomical remodeling is characterized by LV dilatation, hypertrophy, and geometrical remodeling (the heart becomes more spherical). 
a

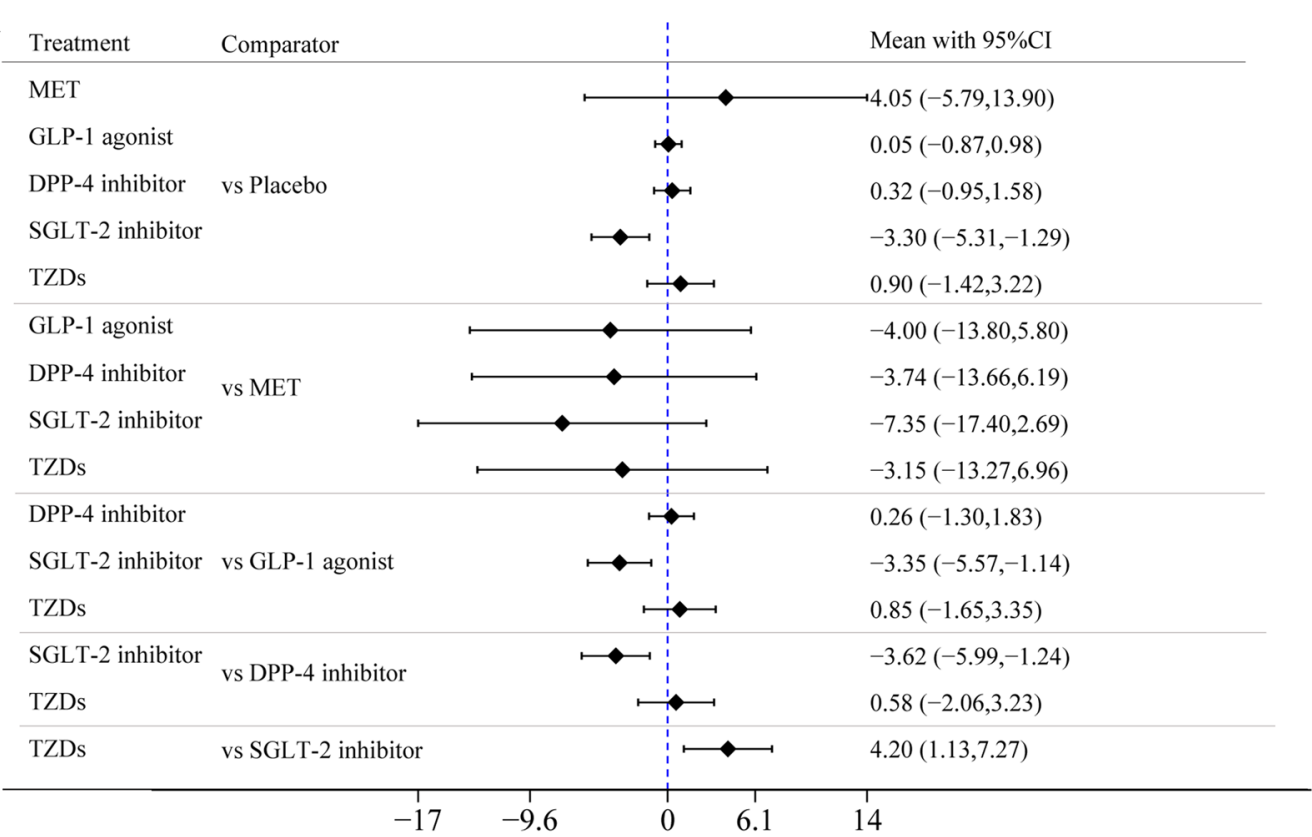

b

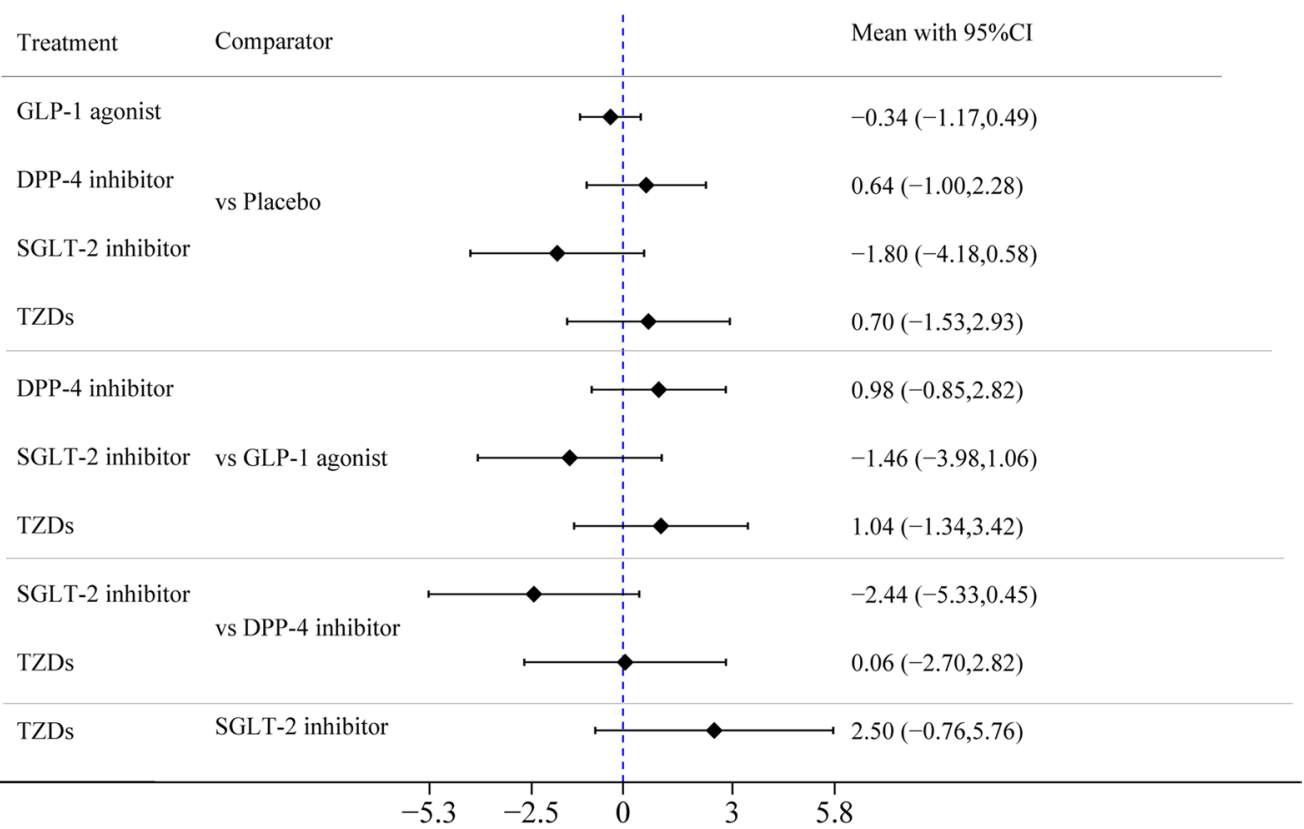

Fig. 4 a Forest plot of mean difference of LVEDD. $\mathbf{b}$ Forest plot of mean difference of LVESD

Our meta-analysis revealed that GLP-1 agonist treatment triggered an increase in the mean change in LVEF\% of $2.04 \%$ and a decrease in mean change in LVESV of $4.39 \mathrm{ml}$ compared with placebo treatment. GLP-1 agonists were also demonstrated to significantly reduce E/e. Our subgroup analysis suggested that GLP-1 agonists had a better effect on diabetic patients with CVD than patients with CVD alone. GLP-1 agonists [61] are an incretin hormone secreted mainly by intestinal L-cells in response to the presence of nutrients. GLP-1 agonists mimic the effects of the native GLP-1 receptor, which increases insulin secretion, inhibits glucagon secretion, increases satiety and slows gastric emptying [33, 62]. However, the mechanism by which GLP-1 agonists 

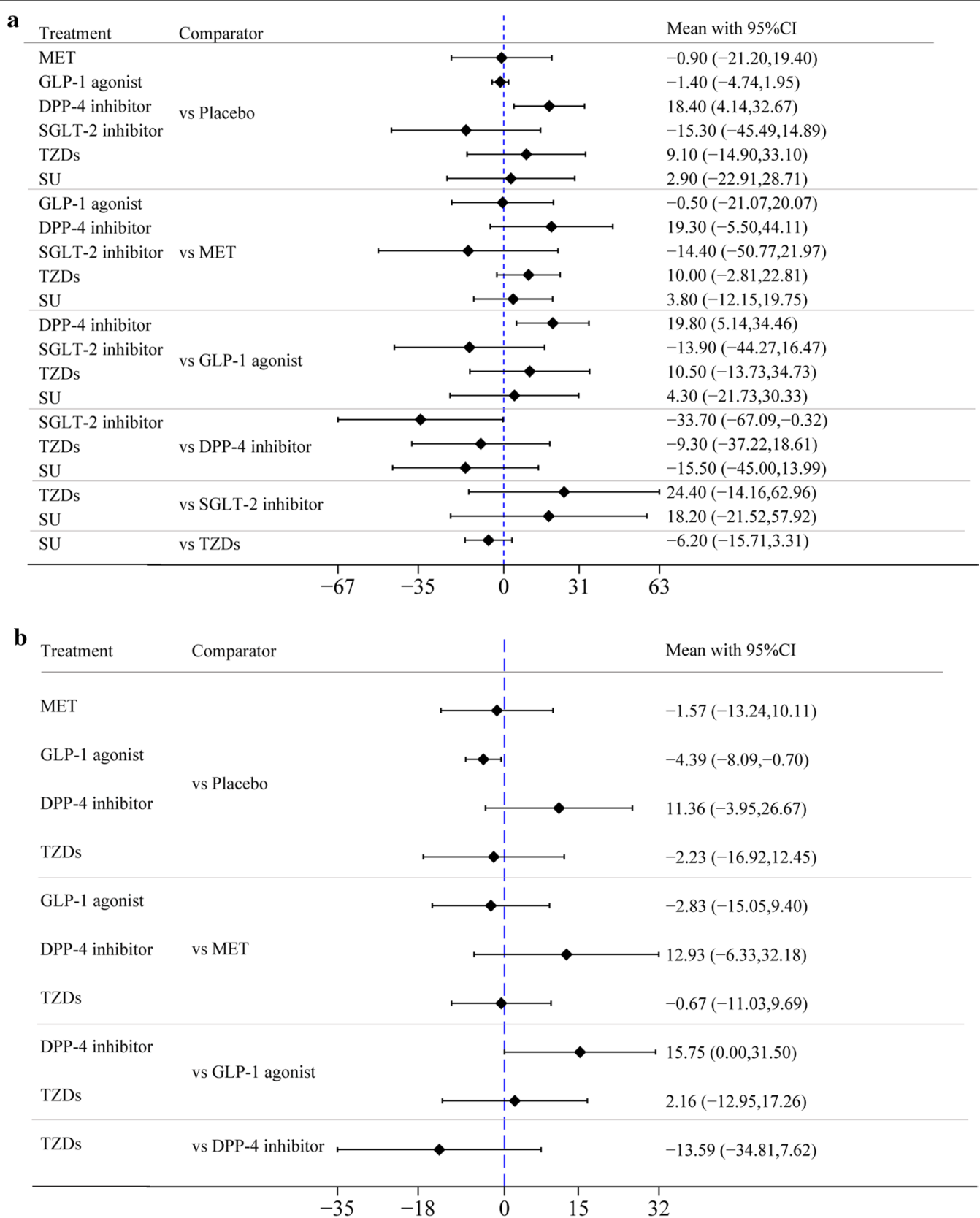

Fig. 5 a Forest plot of mean difference of LVEDV. $\mathbf{b}$ Forest plot of mean difference of LVESV

exert their cardiovascular protective action, especially to improve ventricular remodeling, is still unclear. It was reported that liraglutide, one kind of GLP-1 agonist, inhibited angiotensin II and pressure overload-induced cardiac remodeling by regulating PI3K/Akt1 and AMPK $\alpha$ signaling [63]. Wang et al. [64] also found that the cardiac protection of GLP-1 agonists might be dependent on inhibition of oxidative stress through the mammalian target of rapamycin complex 1/p70 ribosomal protein S6 kinase pathway. In addition to their weight loss and glucose-lowering effects, GLP-1 agonists have been shown to protect the heart during acute ischemia and improve mitochondrial function, microvascular function, and myocardial glucose uptake in experimental animal models of heart failure [41, 65]. Giblett et al. [61] found that GLP-1 agonists are present in left ventricular cardiomyocytes but are not expressed in vascular tissue, so GLP-1 agonists may have direct ventricular effects and mediate 


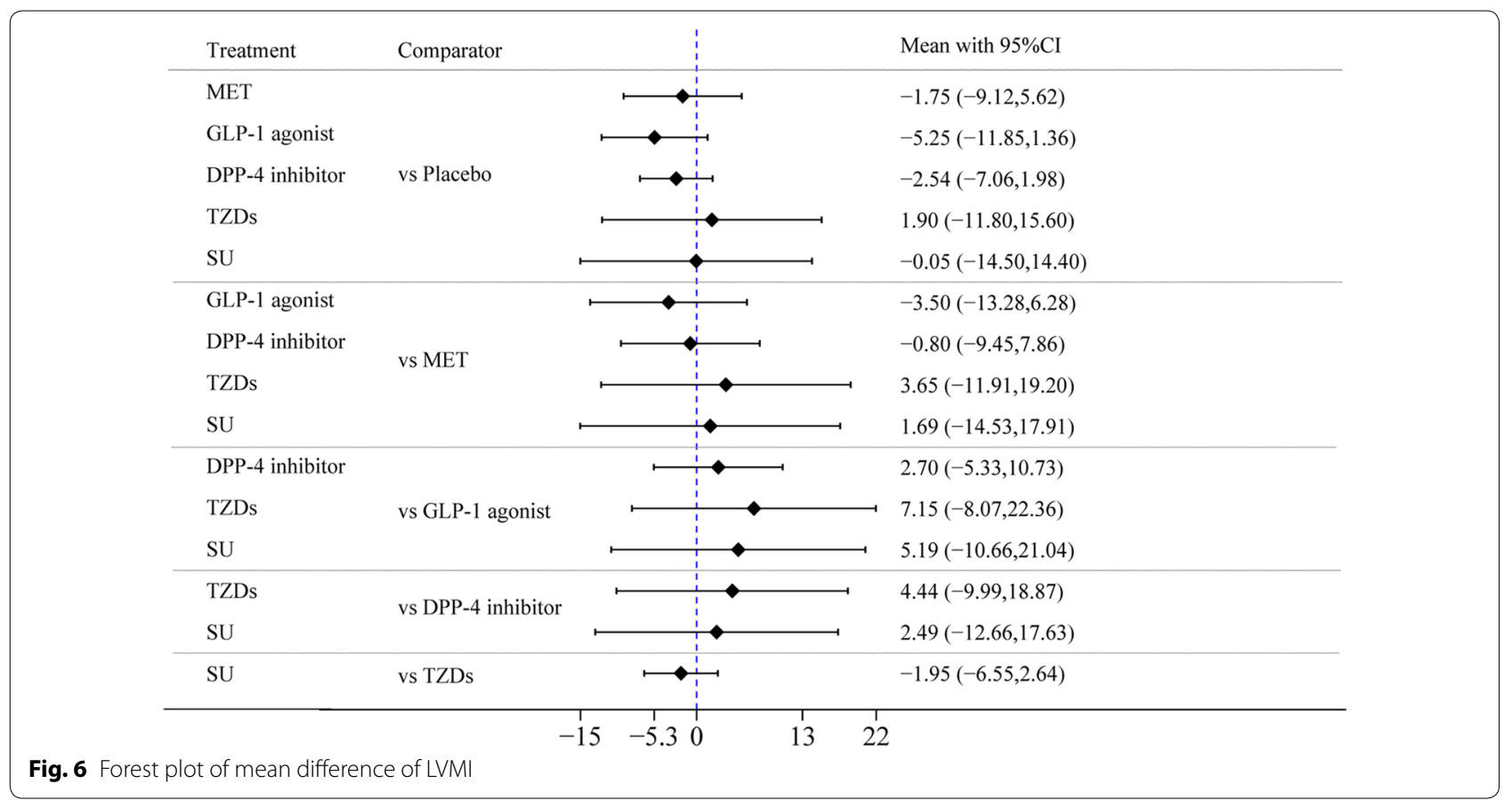

secondary vasodilation through ventricular artery interactions. In addition, GLP-1 agonists increase natriuresis [17], reduce blood pressure, reduce inflammation, reduce ischemic injury, increase heart rate, increase plaque stabilization and decrease smooth muscle proliferation. It has been suggested that the positive effects of GLP-1 agonists on cardiovascular disease may be the result of a direct action on the arteriosclerotic process [66]. All these processes may leave an imprint on GLP-1 agonists' role in the improvement of ventricular remodeling.

The results of our study revealed that SGLT-2 inhibitors could significantly reduce LVEDD but could not exert a significant effect on LVEDV. However, SGLT-2 inhibitors could significantly reduce $\mathrm{E} / \mathrm{e}^{\prime}$ and improve diastolic function of the left ventricle. Some studies suggested that SGLT-2 inhibitors could reduce oxidative stress [66], thereby improving arteriosclerosis and endothelial dysfunction. Experimental data in obese and diabetic mice demonstrated that the SGLT-2 inhibitor empagliflozin significantly ameliorated cardiac fibrosis, coronary arterial thickening, and cardiac macrophage infiltration, suggesting a direct cardiac effect along with an attenuation of oxidative stress on the myocardium [67]. Previous studies have indicated that SGLT1 receptors are predominantly expressed in the human intestine, and the higher selectivity of SGLT1 receptors could lower the variations in postprandial blood glucose, which might help to reduce heart failure risk. These factors collectively could play a crucial role in reducing the vasculopathy burden on the heart.
Other potential beneficial mechanisms, for instance, improved arterial compliance and so on, have also been postulated $[67,68]$. Another study found that SGLT-2 inhibitors in addition to tofogliflozin administration had a favorable effect on left ventricular systolic and diastolic function in patients with T2DM [65, 69-71]. A network meta-analysis of 91 randomized trials by Yang et al. also found that in terms of heart failure risk, sodium-glucose cotransporters 2 were the most favorable option among all classes of antidiabetic medications [72]. Although SGLT-2 inhibitors seemed to reduce the risk of heart failure, Shao et al. considered that dapagliflozin might have greater effects on heart failure reduction compared to empagliflozin [73]. This study has shown the effect of SGLT-2 inhibitors on improving LVEDD but not on improving LVEDV. There is a need for much more research in the future due to the paucity of studies on SGLT-2 inhibitors and involved patients.

Of note, in 2018, a network meta-analysis involving 236 studies and 176,310 subjects found that GLP-1 agonists and SGLT-2 inhibitors were significantly associated with lower cardiovascular mortality than were the control treatments, and SGLT-2 inhibitors were associated with a reduction in heart failure events and myocardial infarction. This study is consistent with our results.

Although MET did not exert an effect on ventricular remodeling in our conclusion, a number of experimental and clinical studies have demonstrated that MET had a beneficial effect on lipids, atherosclerotic thrombosis, 
a

Treatment

MET

Comparator

Mean with $95 \% \mathrm{Cl}$

GLP-1 agonist

DPP-4 inhibitor

SGLT-2 inhibitor vs Placebo

TZDs

$\mathrm{SU}$

GLP-1 agonist

DPP-4 inhibitor

SGLT-2 inhibitor vs MET

TZDs

SU

DPP-4 inhibitor

SGLT-2 inhibitor vs GLP-1 agonist

TZDs

SU

SGLT-2 inhibitor

TZDs vs DPP-4 inhibitor

SU

TZDs

SU
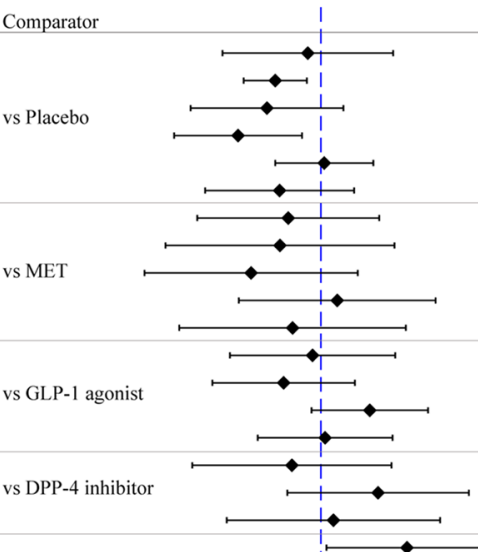

$-0.30(-2.27,1.67)$

$-1.05(-1.78,-0.32)$

$-1.24(-3.01,0.52)$

$-1.91(-3.39,-0.43)$

$0.08(-1.05,1.21)$

$-0.95(-2.67,0.77)$

$-0.75(-2.85,1.35)$

$-0.94(-3.59,1.70)$

$-1.61(-4.07,0.85)$

$0.38(-1.89,2.65)$

$-0.65(-3.27,1.96)$

$-0.19(-2.10,1.72)$

$-0.19(-2.10,1.72)$
$-0.86(-2.51,0.79)$

$1.13(-0.21,2.48)$

$0.10(-1.46,1.66)$

$-0.67(-2.97,1.63)$

SU

vs SGLT-2 inhibitor

$1.32(-0.77,3.42)$

$0.29(-2.17,2.75)$

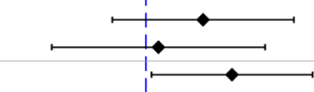

$1.99(0.13,3.85)$

$0.96(-1.31,3.23)$

$-1.03(-3.09,1.03)$

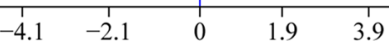

b

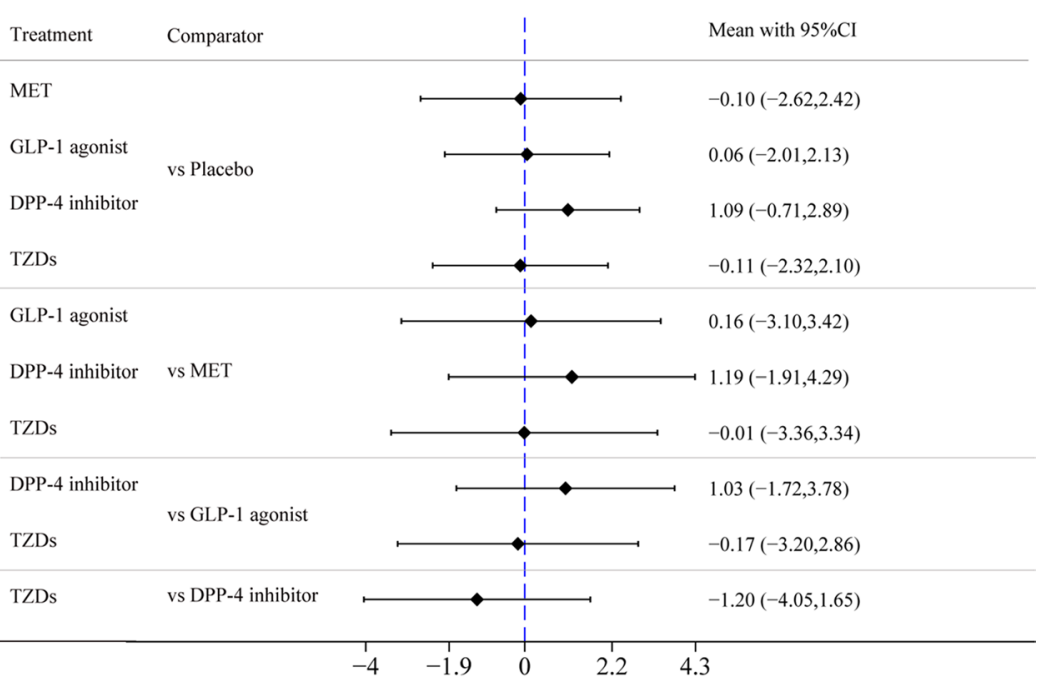

c

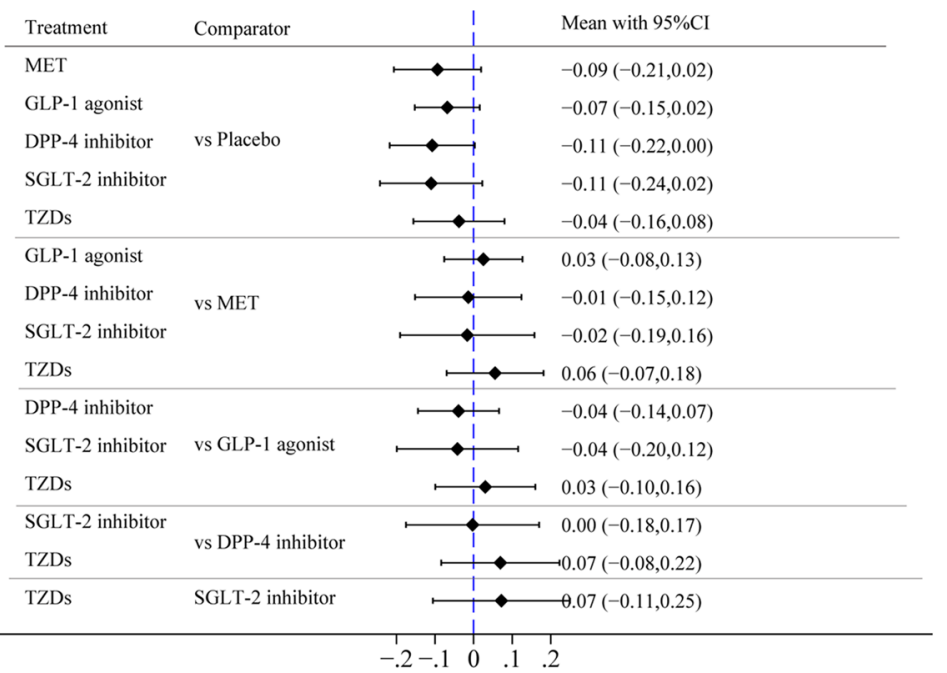

Fig. 7 a Forest plot of mean difference of E/e.' b Forest plot of mean difference of e'. c Forest plot of mean difference of E/A 
inflammation, endothelial function, oxidative stress, and antiproliferative and neuroprotective properties. Based on these findings, the recently published guidelines of the American Diabetes Association and the European Association for the Study of Diabetes recommended [74] either SGLT-2 inhibitors or GLP-1 agonists in patients with T2DM who are unable to achieve their target level of glycemic control with MET. Based on our results, MET treatment in combination with GLP-1 agonists or SGLT-2 inhibitors may also be a good choice for type 2 diabetic patients with cardiovascular disease.

Our results suggested that DPP-4 inhibitors exerted a significant negative impact on LVEDV. Zheng et al. [75] also found in their meta-analysis that the use of DPP-4 inhibitors was not associated with lower mortality than placebo or no treatment and that the use of SGLT-2 inhibitors or GLP-1 agonists was associated with lower mortality than DPP-4 inhibitors. Studies have found that DPP-4 inhibitor therapy did not increase the overall risk of major cardiovascular and renal outcomes but increased the hospitalization rate for heart failure [76]. Uncleaved brain natriuretic peptides, which are known to be substrates of the enzyme DPP-4, might be associated with decompensated HF [77]. Moreover, an increase in LVEDV should result in an increase in the ejection fraction according to the Frank-Starling law. However, our study found that although LVEDV increased with the use of DPP-4 inhibitors, LVEF did not increase. McMurray et al. found that vildagliptin had no major effect on LVEF but did lead to an increase in left ventricular volumes with type 2 diabetes and heart failure [38]. This finding was consistent with our results. A lack of EF increase suggests a negative impact of DPP-4 inhibitors on myocardial contractility. Studies have reported that DPP-4 inhibition is accompanied by increases in myocardial CAMP, which are related to potentiation of endogenous GLP-1. The increases in cAMP may exacerbate the clinical course of heart failure [78, 79]. DPP-4 inhibition might exacerbate the clinical course of heart failure via pathways of SDF-1 (stromal cell-derived factor 1)/CaMKII $\left(\mathrm{Ca}^{2+} /\right.$ calmodulin-dependent protein kinase II). These factors collectively might damage cardiomyocytes, which may be the reason why LVEDV increased, but LVEF did not [80]. Therefore, this result suggests that we should be cautious about the use of DPP-4 inhibitors in type 2 diabetic patients with cardiovascular disease because DPP-4 inhibitors may have adverse effects on cardiac function.

\section{Limitations}

First, this paper included studies that covered three types of patients: one was type 2 diabetic patients, another was cardiovascular patients, and the third was patients with comorbidities of the first two. This may lead to betweenstudies heterogeneity and exert a certain impact on the combined results. Second, given that the sample size of the included studies ranged from 15 to 559, there was a lack of controlled clinical trials with a large sample size to conduct a more powerful demonstration of our outcome. Third, the variability of the ventricular structural changes estimated by echocardiography may exaggerate or ignore the therapeutic effect, leading to between-studies heterogeneity.

\section{Conclusions}

As this network meta-analysis shows, GLP-1 agonists are more significantly associated with improved LVEF, LVESV and E/e', SGLT-2 inhibitors are more significantly associated with improved LVEDD and E/e', and DPP-4 inhibitors are more strongly associated with a negative impact on LVEDV than are placebos. SGLT-2 inhibitors are superior to other drugs in pairwise comparisons. Thus, GLP-1 agonist and SGLT-2 inhibitor treatment may serve as novel therapeutics for treating hyperglycemia and reducing cardiovascular comorbidities.

\section{Supplementary information}

Supplementary information accompanies this paper at https://doi. org/10.1186/s12933-020-0987-x.

Additional file 1: Figure S1. Risk of bias graph with RevMan 5.3. Additional file 2: Figure S2. Risk of bias summary with RevMan 5.3. Additional file 3: Table S1. Treatment rankings.

Additional file 4: Figure S3. Funnel plot of mean difference of LVEF\%.

\section{Abbreviations}

CAD: coronary artery disease; CFR: coronary flow reserve; $\mathrm{Cl}$ : confidence interval; CVD: cardiovascular disease; $e^{\prime}$ : early diastolic velocity; $E / e^{\prime}$ : mitral inflow $E$ velocity to tissue Doppler $\mathrm{e}^{\prime}$ ratio; E/A: early diastolic to late diastolic velocities ratio; DPP-4: dipeptidyl peptidase-4; GLP-1: glucagon-like peptide-1; HF: heart failure; LVEDD: LV end-diastolic diameter; LVEDV: LV end-diastolic volume; LVEF: left ventricular ejection fraction; LVESD: LV end-systolic diameter; LVESV: LV end-systolic volume; LVMI: LV mass index; MD: mean difference; MET: metformin; RCT: randomized controlled trial; SGLT-2: sodium glucose cotransporter type 2; SU: sulfonylurea; T2DM: type 2 diabetes mellitus; TZDs: thiazolidinediones; STEMI: ST-segment elevation myocardial ischemia; SUCRA: surface under the cumulative ranking curve.

\footnotetext{
Acknowledgements

We would like to thank Beijing Zhiyun data technology co. LTD for providing data analysis service.

Authors' contributions

DPZ contributed substantially to conception and design, acquisition of data, analysis and interpretation of data, and drafted the article. LX design the study,revised it critically for important intellectual content, gave final approval of the version to be published, and agreed to act as guarantor of the work. LFW and HJW contributed acquisition of data, analysis and interpretation of data. FJ designed the study and revised it critically for important intellectual content. All authors read and approved the final manuscript.
} 


\section{Funding}

There were no sources of funding for this research.

\section{Availability of data and materials}

Not applicable.

\section{Ethics approval and consent to participate}

Not applicable.

\section{Consent for publication}

Not applicable.

\section{Competing interests}

The authors declare that they have no competing interests.

Received: 14 November 2019 Accepted: 11 January 2020

Published online: 22 January 2020

\section{References}

1. Abraham WT, Ponikowski P, Brueckmann M, Zeller C, Macesic H, Peil B, et al. Rationale and design of the EMPERIAL-Preserved and EMPERIALReduced trials of empagliflozin in patients with chronic heart failure. Eur J Heart Fail. 2019;21(7):932-42.

2. Zinman B, Wanner C, Lachin JM, Fitchett D, Bluhmki E, Hantel S, et al. Empagliflozin, cardiovascular outcomes, and mortality in type 2 diabetes. N Engl J Med. 2015;373(22):2117-28.

3. Sokos GG, Bolukoglu H, German J, Hentosz T, Magovern GJ Jr, Maher TD, et al. Effect of glucagon-like peptide-1 (GLP-1) on glycemic control and left ventricular function in patients undergoing coronary artery bypass grafting. Am J Cardiol. 2007;100(5):824-9.

4. Read PA, Hoole SP, White PA, Khan FZ, O'Sullivan M, West NEJ, et al. A pilot study to assess whether glucagon-like peptide-1 protects the heart from ischemic dysfunction and attenuates stunning after coronary balloon occlusion in humans. Circulation. 2011:4(3):266-72.

5. Read PA, Khan FZ, Dutka DP. Cardioprotection against ischaemia induced by dobutamine stress using glucagon-like peptide- 1 in patients with coronary artery disease. Heart. 2012;98(5):408-13.

6. Loi H, Boal F, Tronchere H, Cinato M, Kramar S, Oleshchuk O, et al. Metformin protects the heart against hypertrophic and apoptotic remodeling after myocardial infarction. Front Pharmacol. 2019;10:154.

7. Younis A, Eskenazi D, Goldkorn R, Leor J, Naftali-Shani N, Fisman EZ, et al. The addition of vildagliptin to metformin prevents the elevation of interleukin $1 \beta$ in patients with type 2 diabetes and coronary artery disease: a prospective, randomized, open-label study. Cardiovasc Diabetol. 2017;16(1):69

8. Charytan DM, Solomon SD, Ivanovich P, Remuzzi G, Cooper ME, McGill $J B$, et al. Metformin use and cardiovascular events in patients with type 2 diabetes and chronic kidney disease. Diabetes Obes Metab. 2019;21(5):1199-208.

9. Han Y, Xie H, Liu Y, Gao P, Yang X, Shen Z. Effect of metformin on all-cause and cardiovascular mortality in patients with coronary artery diseases: a systematic review and an updated meta-analysis. Cardiovasc Diabetol. 2019;18(1):96.

10. Wägner AM, Miranda-Calderín G, Ugarte-Lopetegui MA, Marrero-Santiago H, Suárez-Castellano L, López-Madrazo MJ, et al. Effect of liraglutide on physical performance in type 2 diabetes: results of a randomized, double-blind, controlled trial (LIPER2). Diabetes Metab. 2019;45(3):268-75.

11. Chen WR, Chen YD, Tian F, Yang N, Cheng LQ, Hu SY, et al. Effects of liraglutide on reperfusion injury in patients with ST-segment-elevation myocardial infarction. Circ Cardiovasc Imaging. 2016;9(12):e005146.

12. Kato S, Fukui K, Kirigaya H, Gyotoku D, linuma N, Kusakawa Y, et al. Inhibition of DPP-4 by alogliptin improves coronary flow reserve and left ventricular systolic function evaluated by phase contrast cine magnetic resonance imaging in patients with type 2 diabetes and coronary artery disease. Int J Cardiol. 2016;223:770-5.

13. Santos-Gallego CG, Requena-Ibanez JA, San Antonio R, Ishikawa K, Watanabe S, Picatoste B, et al. Empagliflozin ameliorates adverse left ventricular remodeling in nondiabetic heart failure by enhancing myocardial energetics. J Am Coll Cardiol. 2019;73(15):1931-44.
14. Liberati A, Altman DG, Tetzlaff J, Mulrow C, Gotzsche PC, loannidis JP, et al. The PRISMA statement for reporting systematic reviews and meta-analyses of studies that evaluate healthcare interventions: explanation and elaboration. BMJ. 2009;339:b2700.

15. Al Ali L, Hartman MT, Lexis CP, Hummel YM, Lipsic E, van Melle JP, et al. The effect of metformin on diastolic function in patients presenting with ST-elevation myocardial infarction. PLoS ONE. 2016;1 1(12):e0168340.

16. Arturi F, Succurro E, Miceli S, Cloro C, Ruffo M, Maio R, et al. Liraglutide improves cardiac function in patients with type 2 diabetes and chronic heart failure. Endocrine. 2017;57(3):464-73.

17. Bizino MB, Jazet IM, Westenberg JJM, van Eyk HJ, Paiman EHM, Smit JWA, et al. Effect of liraglutide on cardiac function in patients with type 2 diabetes mellitus: randomized placebo-controlled trial. Cardiovasc Diabetol. 2019;18(1):55

18. Bonora BM, de Vigili Kreutzenberg S, Avogaro A, Fadini GP. Effects of the SGLT2 inhibitor dapagliflozin on cardiac function evaluated by impedance cardiography in patients with type 2 diabetes. Secondary analysis of a randomized placebo-controlled trial. Cardiovasc Diabetol. 2019;18(1):106.

19. Brenner C, Adrion C, Grabmaier U, Theisen D, von Ziegler F, Leber A, et al. Sitagliptin plus granulocyte colony-stimulating factor in patients suffering from acute myocardial infarction: a double-blind, randomized placebo-controlled trial of efficacy and safety (SITAGRAMI trial). Int J Cardiol. 2016;205:23-30.

20. Chen WJY, Diamant M, de Boer K, Harms HJ, Robbers L, van Rossum AC, et al. Effects of exenatide on cardiac function, perfusion, and energetics in type 2 diabetic patients with cardiomyopathy: a randomized controlled trial against insulin glargine. Cardiovasc Diabetol. 2017;16(1):67.

21. Chen WR, Shen XQ, Zhang Y, Chen YD, Hu SY, Qian G, et al. Effects of liraglutide on left ventricular function in patients with non-ST-segment elevation myocardial infarction. Endocrine. 2016;52(3):516-26.

22. Chen WR, Hu SY, Chen YD, Zhang Y, Qian G, Wang J, et al. Effects of liraglutide on left ventricular function in patients with ST-segment elevation myocardial infarction undergoing primary percutaneous coronary intervention. Am Heart J. 2015;170(5):845-54.

23. Cohen ND, Gutman SJ, Briganti EM, Taylor AJ. Effects of empagliflozin treatment on cardiac function and structure in patients with type 2 diabetes: a cardiac magnetic resonance study. Intern Med J. 2019;49(8):1006-10.

24. Ghazzi MN, Perez JE, Antonucci TK, Driscoll JH, Huang SM, Faja BW, et al. Cardiac and glycemic benefits of troglitazone treatment in NIDDM. The Troglitazone Study Group. Diabetes. 1997:46(3):433-9.

25. Giles TD, Miller AB, Elkayam U, Bhattacharya M, Perez A. Pioglitazone and heart failure: results from a controlled study in patients with type 2 diabetes mellitus and systolic dysfunction. J Cardiac Fail. 2008;14(6):445-52.

26. Halbirk M, Nørrelund H, Møller N, Holst JJ, Schmitz O, Nielsen R, et al. Cardiovascular and metabolic effects of 48-h glucagon-like peptide-1 infusion in compensated chronic patients with heart failure. Am J Physiol. 2010;298(3):H1096-102.

27. Hiramatsu T, Asano Y, Mabuchi M, Imai K, Iguchi D, Furuta S. Liraglutide relieves cardiac dilated function than DPP-4 inhibitors. Eur J Clin Invest. 2018;48(10):e13007.

28. Hiramatsu T, Ozeki A, Asai K, Saka M, Hobo A, Furuta S. Liraglutide improves glycemic and blood pressure control and ameliorates progression of left ventricular hypertrophy in patients with type 2 diabetes mellitus on peritoneal dialysis. Therap Apheresis Dial. 2015;19(6):598-605.

29. Jorgensen PG, Jensen MT, Mensberg P, Storgaard H, Nyby S, Jensen JS, et al. Effect of exercise combined with glucagon-like peptide-1 receptor agonist treatment on cardiac function: a randomized double-blind placebo-controlled clinical trial. Diabetes Obes Metab. 2017;19(7):1040-4.

30. Jorsal A, Kistorp C, Holmager P, Tougaard RS, Nielsen R, Hänselmann A, et al. Effect of liraglutide, a glucagon-like peptide-1 analogue, on left ventricular function in stable chronic heart failure patients with and without diabetes (LIVE) — a multicentre, double-blind, randomised, placebocontrolled trial. Eur J Heart Fail. 2017;19(1):69-77.

31. Kumarathurai P, Anholm C, Nielsen OW, Kristiansen OP, Molvig J, Madsbad $\mathrm{S}$, et al. Effects of the glucagon-like peptide-1 receptor agonist liraglutide on systolic function in patients with coronary artery disease and type 2 diabetes: a randomized double-blind placebo-controlled crossover study. Cardiovasc Diabetol. 2016;15(1):105. 
32. Lambadiari V, Pavlidis G, Kousathana F, Varoudi M, Vlastos D, Maratou $E$, et al. Effects of 6-month treatment with the glucagon like peptide-1 analogue liraglutide on arterial stiffness, left ventricular myocardial deformation and oxidative stress in subjects with newly diagnosed type 2 diabetes. Cardiovasc Diabetol. 2018;17(1):8.

33. Lepore JJ, Olson E, Demopoulos L, Haws T, Fang Z, Barbour AM, et al. Effects of the novel long-acting GLP-1 agonist, albiglutide, on cardiac function, cardiac metabolism, and exercise capacity in patients with chronic heart failure and reduced ejection fraction. JACC Heart Fail. 2016;4(7):559-66

34. Leung M, Leung DY, Wong VW. Effects of dipeptidyl peptidase-4 inhibitors on cardiac and endothelial function in type 2 diabetes mellitus: a pilot study. Diabetes Vasc Dis Res. 2016;13(3):236-43.

35. Lips M, Mraz M, Klouckova J, Kopecky P, Dobias M, Krizova J, et al. Effect of continuous exenatide infusion on cardiac function and peri-operative glucose control in patients undergoing cardiac surgery: a single-blind, randomized controlled trial. Diabetes Obes Metab. 2017;19(12):1818-22.

36. Liu Y, Jiang X, Chen X. Liraglutide and Metformin alone or combined therapy for type 2 diabetes patients complicated with coronary artery disease. Lipids Health Dis. 2017;16(1):227.

37. Margulies KB, Hernandez AF, Redfield MM, Givertz MM, Oliveira GH, Cole $\mathrm{R}$, et al. Effects of liraglutide on clinical stability among patients with advanced heart failure and reduced ejection fraction: a randomized clinical trial. JAMA. 2016;316(5):500-8.

38. McMurray JJV, Ponikowski P, Bolli GB, Lukashevich V, Kozlovski P, Kothny W et al. Effects of vildagliptin on ventricular function in patients with type 2 diabetes mellitus and heart failure: a randomized placebo-controlled trial. JACC Heart Fail. 2018;6(1):8-17.

39. Mohan M, Al-Talabany S, McKinnie A, Mordi I, Singh J, Gandy S, et al. A randomized controlled trial of metformin on left ventricular hypertrophy in patients with coronary artery disease without diabetes: the METREMODEL trial. Eur Heart J. 2019;40(41):3409-17.

40. Naka K, Pappas K, Papathanassiou K, Papamichael N, Kazakos N, Kanioglou C, et al. Lack of effects of pioglitazone on cardiac function in patients with type 2 diabetes and evidence of left ventricular diastolic dysfunction: a tissue doppler imaging study. Cardiovasc Diabetol. 2010;9:57.

41. Nielsen R, Jorsal A, Iversen P, Tolbod LP, Bouchelouche K, Sørensen J, et al. Effect of liraglutide on myocardial glucose uptake and blood flow in stable chronic heart failure patients: a double-blind, randomized, placebo-controlled LIVE sub-study. J Nucl Cardiol. 2019;26(2):585-97.

42. Nikolaidis LA, Mankad S, Sokos GG, Miske G, Shah A, Elahi D, et al. Effects of glucagon-like peptide-1 in patients with acute myocardial infarction and left ventricular dysfunction after successful reperfusion. Circulation. 2004;109(8):962-5.

43. Nogueira K, Furtado M, Fukui R, Correia M, Dos SR, Andrade J, et al. Left ventricular diastolic function in patients with type 2 diabetes treated with a dipeptidyl peptidase-4 inhibitor-a pilot study. Diabetol Metab Syndrome. 2014;6(1):103.

44. Nozue T, Yamada M, Tsunoda T, Katoh H, Ito S, Iwaki T, et al. Effects of liraglutide, a glucagon-like peptide-1 analog, on left ventricular remodeling assessed by cardiac magnetic resonance imaging in patients with acute myocardial infarction undergoing primary percutaneous coronary intervention. Heart Vessels. 2016;31(8):1239-46.

45. Nystrom T, Santos I, Hedberg F, Wardell J, Witt N, Cao Y, et al. Effects on subclinical heart failure in type 2 diabetic subjects on liraglutide treatment vs. glimepiride both in combination with metformin: a randomized open parallel-group study. Front Endocrinol. 2017;8:325.

46. Oe H, Nakamura K, Kihara H, Shimada K, Fukuda S, Takagi T, et al. Comparison of effects of sitagliptin and voglibose on left ventricular diastolic dysfunction in patients with type 2 diabetes: results of the 3D trial. Cardiovasc Diabetol. 2015;14:83.

47. Otagaki M, Matsumura K, Kin H, Fujii K, Shibutani H, Matsumoto H, et al. Effect of tofogliflozin on systolic and diastolic cardiac function in type 2 diabetic patients. Cardiovasc Drugs Ther. 2019;33(4):435-42.

48. Ozawa T, Oda H, Oda M, Hosaka Y, Kashimura T, Ozaki K, et al. Improved cardiac function after sirolimus-eluting stent placement in diabetic patients by pioglitazone: combination therapy with statin. J Cardiol. 2009;53(3):402-9.

49. Sardu C, Paolisso P, Sacra C, Santamaria M, De Lucia C, Ruocco A, et al. Cardiac resynchronization therapy with a defibrillator (CRTd) in failing heart patients with type 2 diabetes mellitus and treated by glucagon-like peptide 1 receptor agonists (GLP-1 RA) therapy vs. conventional hypoglycemic drugs: Arrhythmic burden, hospitalizations for heart failure, and CRTd responders rate. Cardiovasc Diabetol. 2018;17(1):137.

50. Scognamiglio R, Avogaro A, de Vigili Kreutzenberg S, Negut C, Palisi M, Bagolin E, et al. Effects of treatment with sulfonylurea drugs or insulin on ischemia-induced myocardial dysfunction in type 2 diabetes. Diabetes. 2002;51(3):808-12.

51. Sokos GG, Nikolaidis LA, Mankad S, Elahi D, Shannon RP. Glucagonlike peptide-1 infusion improves left ventricular ejection fraction and functional status in patients with chronic heart failure. J Cardiac Fail. 2006;12(9):694-9.

52. Sutton MSJ, Rendell M, Dandona P, Dole JF, Murphy K, Patwardhan R, et al. A comparison of the effects of rosiglitazone and glyburide on cardiovascular function and glycemic control in patients with type 2 diabetes. Diabetes Care. 2002;25(11):2058-64.

53. Türkmen Kemal Y, Güvener Demirag N, Yildirir A, Atar A, Dogruk Unal A, Biyiklioglu Z. Effects of rosiglitazone on plasma brain natriuretic peptide levels and myocardial performance index in patients with type 2 diabetes mellitus. Acta Diabetol. 2007;44(3):149-56.

54. van der Meer RW, Rijzewijk LJ, de Jong HW, Lamb HJ, Lubberink M, Romijn JA, et al. Pioglitazone improves cardiac function and alters myocardial substrate metabolism without affecting cardiac triglyceride accumulation and high-energy phosphate metabolism in patients with well-controlled type 2 diabetes mellitus. Circulation. 2009;119(15):2069-77.

55. Wong AK, Symon R, AlZadjali MA, Ang DS, Ogston S, Choy A, et al. The effect of metformin on insulin resistance and exercise parameters in patients with heart failure. Eur J Heart Fail. 2012;14(11):1303-10.

56. Woo JS, Kim W, Ha SJ, Kim JB, Kim SJ, Kim WS, et al. Cardioprotective effects of exenatide in patients with ST-segment-elevation myocardial infarction undergoing primary percutaneous coronary intervention: results of exenatide myocardial protection in revascularization study. Arterioscler Thromb Vasc Biol. 2013;33(9):2252-60.

57. Yamada H, Tanaka A, Kusunose K, Amano R, Matsuhisa M, Daida H, et al. Effect of sitagliptin on the echocardiographic parameters of left ventricular diastolic function in patients with type 2 diabetes: a subgroup analysis of the PROLOGUE study. Cardiovasc Diabetol. 2017;16(1):63.

58. Yamamoto M, Seo Y, Ishizu T, Nishi I, Hamada-Harimura Y, MachinoOhtsuka T, et al. Effect of dipeptidyl peptidase-4 inhibitors on cardiovascular outcome and cardiac function in patients with diabetes and heart failure- insights from the Ibaraki Cardiac Assessment Study-Heart Failure (ICAS-HF) Registry. Circ J. 2017;81(11):1662-9.

59. Yokoyama J, Sutoh N, Higuma T, Horiuchi D, Katoh C, Yokota T, et al. Efficacy and safety of low-dose pioglitazone after primary coronary angioplasty with the use of bare metal stent in patients with acute myocardial infarction and with type 2 diabetes mellitus or impaired glucose tolerance. Heart Vessels. 2007;22(3):146-51.

60. Zhang JY. Effects of liraglutide on hemodynamic parameters in patients with heart failure. Oncotarget. 2017;8(37):62693-702.

61. Giblett JP, Axell RG, White PA, Aetesam-Ur-Rahman M, Clarke SJ, Figg $\mathrm{N}$, et al. Glucagon-like peptide-1-mediated cardioprotection does not reduce right ventricular stunning and cumulative ischemic dysfunction after coronary balloon occlusion. JACC Basic Transl Sci. 2019;4(2):222-33.

62. Ban K, Noyan-Ashraf MH, Hoefer J, Bolz SS, Drucker DJ, Husain M. Cardioprotective and vasodilatory actions of glucagon-like peptide 1 receptor are mediated through both glucagon-like peptide 1 receptor-dependent and -independent pathways. Circulation. 2008;117(18):2340-50.

63. Li R, Shan Y, Gao L, Wang X, Wang X, Wang F. The Glp-1 analog liraglutide protects against angiotensin ii and pressure overload-induced cardiac hypertrophy via PI3K/Akt1 and AMPKa signaling. Front Pharmacol. 2019;10:537.

64. Wang D, Jiang L, Feng B, He N, Zhang Y, Ye H. Protective effects of glucagon-like peptide-1 on cardiac remodeling by inhibiting oxidative stress through mammalian target of rapamycin complex 1/p70 ribosomal protein $\mathrm{S} 6$ kinase pathway in diabetes mellitus. J Diabetes Investig. 2020;11(1):39-51.

65. Zhao T, Parikh P, Bhashyam S, Bolukoglu H, Poornima I, Shen YT, et al. Direct effects of glucagon-like peptide-1 on myocardial contractility and glucose uptake in normal and postischemic isolated rat hearts. J Pharmacol Exp Ther. 2006;317(3):1106-13. 
66. Kim GS, Park JH, Won JC. The role of glucagon-like peptide 1 receptor agonists and sodium-glucose cotransporter 2 inhibitors in reducing cardiovascular events in patients with type 2 diabetes. Endocrinol Metab. 2019;34(2):106-16.

67. Marx N, McGuire DK. Sodium-glucose cotransporter-2 inhibition for the reduction of cardiovascular events in high-risk patients with diabetes mellitus. Eur Heart J. 2016;37(42):3192-200.

68. Ferrannini E, Mark M, Mayoux E. CV Protection in the EMPA-REG OUTCOME Trial: a "Thrifty Substrate" Hypothesis. Diabetes Care. 2016;39(7):1108-14

69. Ding S, Du YP, Lin N, Su YY, Yang F, Kong LC, et al. Effect of glucagon-like peptide-1 on major cardiovascular outcomes in patients with type 2 diabetes mellitus: a meta-analysis of randomized controlled trials. Int J Cardiol. 2016;222:957-62.

70. Motta AJ, Koska J, Reaven P, Migrino RQ. Vascular protective effects of diabetes medications that mimic or increase glucagon-like peptide-1 activity. Recent Pat Cardiovasc Drug Discov. 2012;7(1):2-9.

71. Bose AK, Mocanu MM, Carr RD, Brand CL, Yellon DM. Glucagon-like peptide 1 can directly protect the heart against ischemia/reperfusion injury. Diabetes. 2005;54(1):146-51

72. Yang DY, He X, Liang HW, Zhang SZ, Zhong XB, Luo CF, et al. Comparative outcomes of heart failure among existent classes of anti-diabetic agents: a network meta-analysis of 171,253 participants from 91 randomized controlled trials. Cardiovasc Diabetol. 2019;18(1):47.

73. Shao SC, Chang KC, Hung MJ, Yang NI, Chan YY, Chen HY, et al. Comparative risk evaluation for cardiovascular events associated with dapagliflozin vs. empagliflozin in real-world type 2 diabetes patients: a multi-institutional cohort study. Cardiovasc Diabetol. 2019;18(1):120.

74. Madsbad S. Liraglutide for the prevention of major adverse cardiovascular events in diabetic patients. Expert Rev Cardiovasc Ther. 2019;17(5):377-87.
75. Zheng SL, Roddick AJ, Aghar-Jaffar R, Shun-Shin MJ, Francis D, Oliver N, et al. Association between use of sodium-glucose cotransporter 2 Inhibitors, glucagon-like peptide 1 agonists, and dipeptidyl peptidase 4 inhibitors with all-cause mortality in patients with type 2 diabetes: a systematic review and meta-analysis. JAMA. 2018;319(15):1580-91.

76. Kim KJ, Choi J, Lee J, Bae JH, An JH, Kim HY, et al. Dipeptidyl peptidase-4 inhibitor compared with sulfonylurea in combination with metformin: cardiovascular and renal outcomes in a propensity-matched cohort study. Cardiovasc Diabetol. 2019;18(1):28.

77. Suh S, Seo GH, Jung CH, Kim MK, Jin SM, Hwang YC, et al. Increased risk of hospitalization for heart failure with newly prescribed dipeptidyl peptidase-4 inhibitors and pioglitazone using the Korean Health Insurance Claims Database. Diabetes Metab J. 2015;39(3):247-52.

78. Packer M. Is the way to someone's heart through their stomach? The cardiorenal paradox of incretin-based hypoglycemic drugs in heart failure. Circ Heart Fail. 2017;10(10):e004551.

79. Aoyama M, Kawase H, Bando YK, Monji A, Murohara T. Dipeptidyl peptidase 4 inhibition alleviates shortage of circulating glucagon-like peptide- 1 in heart failure and mitigates myocardial remodeling and apoptosis via the exchange protein directly activated by cyclic AMP 1/ ras-related protein 1 axis. Circ Heart Fail. 2016;9(1):e002081.

80. Packer M. Do DPP-4 inhibitors cause heart failure events by promoting adrenergically mediated cardiotoxicity? Clues from laboratory models and clinical trials. Circ Res. 2018;122(7):928-32.

\section{Publisher's Note}

Springer Nature remains neutral with regard to jurisdictional claims in published maps and institutional affiliations.
Ready to submit your research? Choose BMC and benefit from:

- fast, convenient online submission

- thorough peer review by experienced researchers in your field

- rapid publication on acceptance

- support for research data, including large and complex data types

- gold Open Access which fosters wider collaboration and increased citations

- maximum visibility for your research: over $100 \mathrm{M}$ website views per year

At BMC, research is always in progress.

Learn more biomedcentral.com/submissions 